\title{
Tandem Addition/Electrocyclization/Benzylation of Alkyl Aryl-1,3-dienes and Aromatic Aldehydes: Access to Highly Substituted Indenes
}

S. K. Mahesh, Jagadeesh Babu Nanubolu, and Gangarajula Sudhakar*

Email: gusudhakar@iict.res.in 
1. ${ }^{1} \mathrm{H}$ NMR and ${ }^{13} \mathrm{C}$ NMR Spectra..............................................................................S2-S44

2. X-ray Crystallography Information.......................................S45-S50

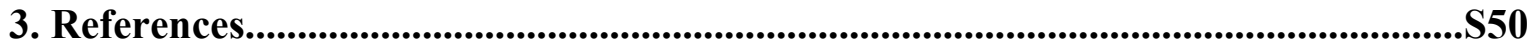




\section{1. ${ }^{1} \mathrm{H}$ and ${ }^{13} \mathrm{C}$ NMR Spectra}
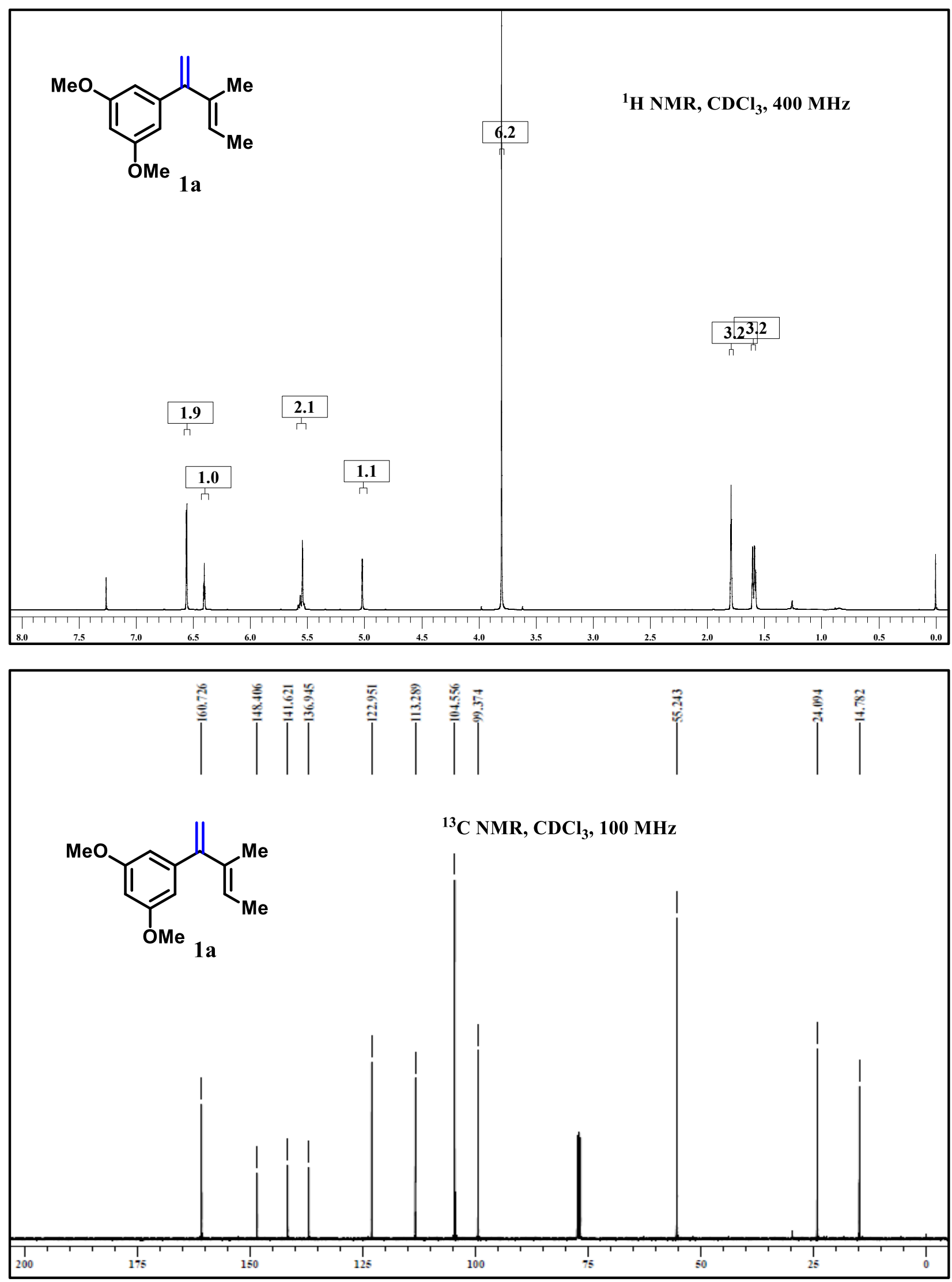

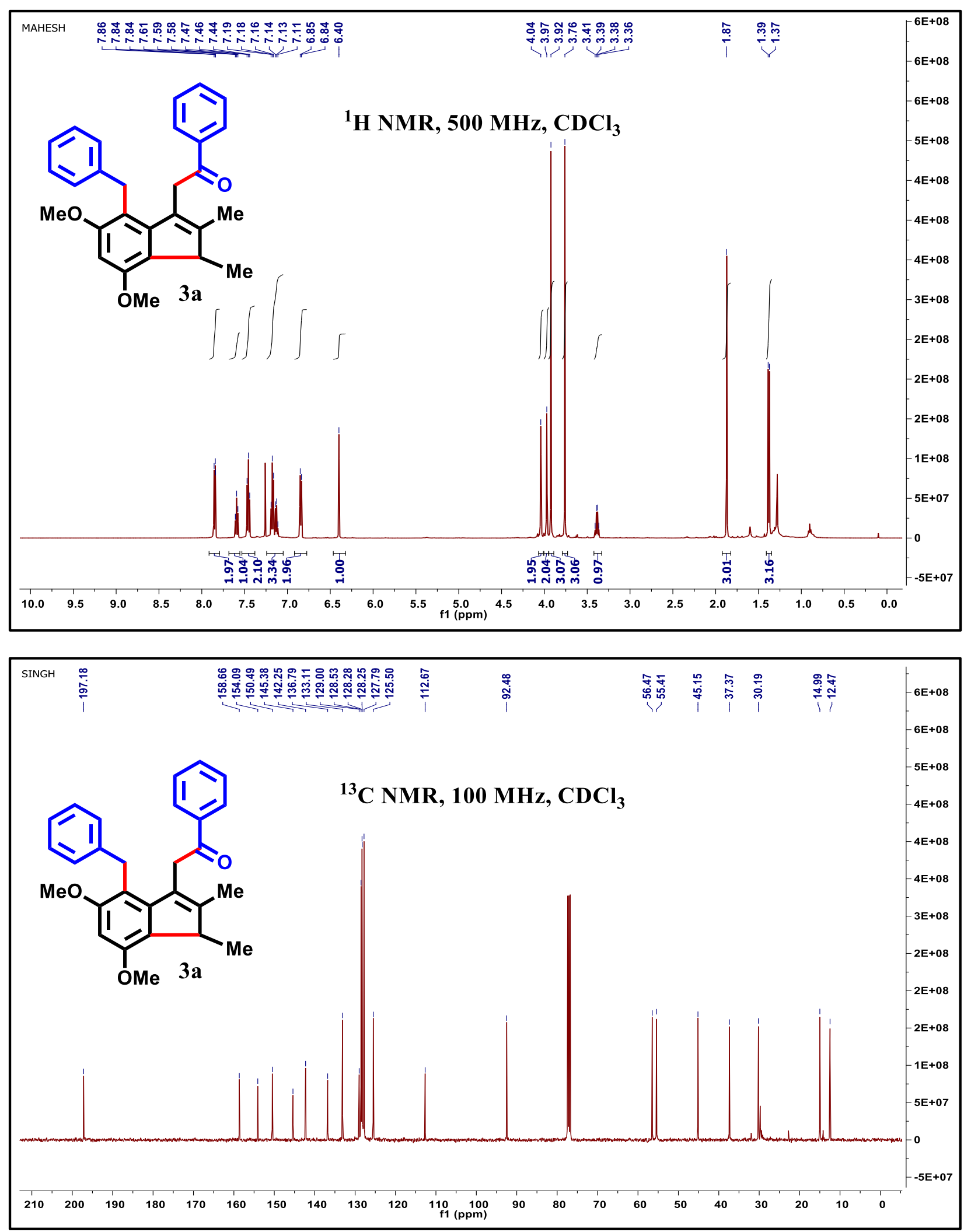


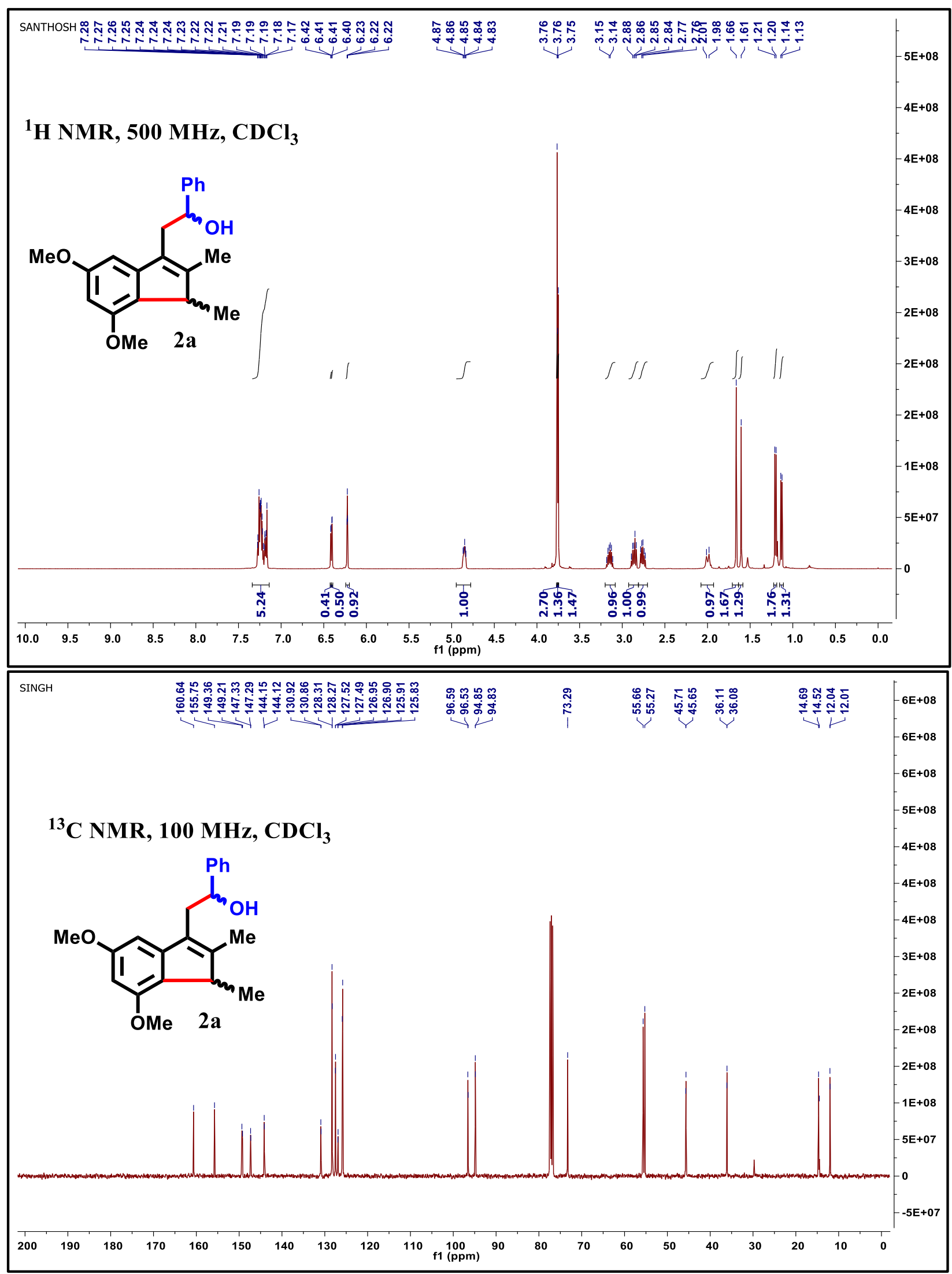



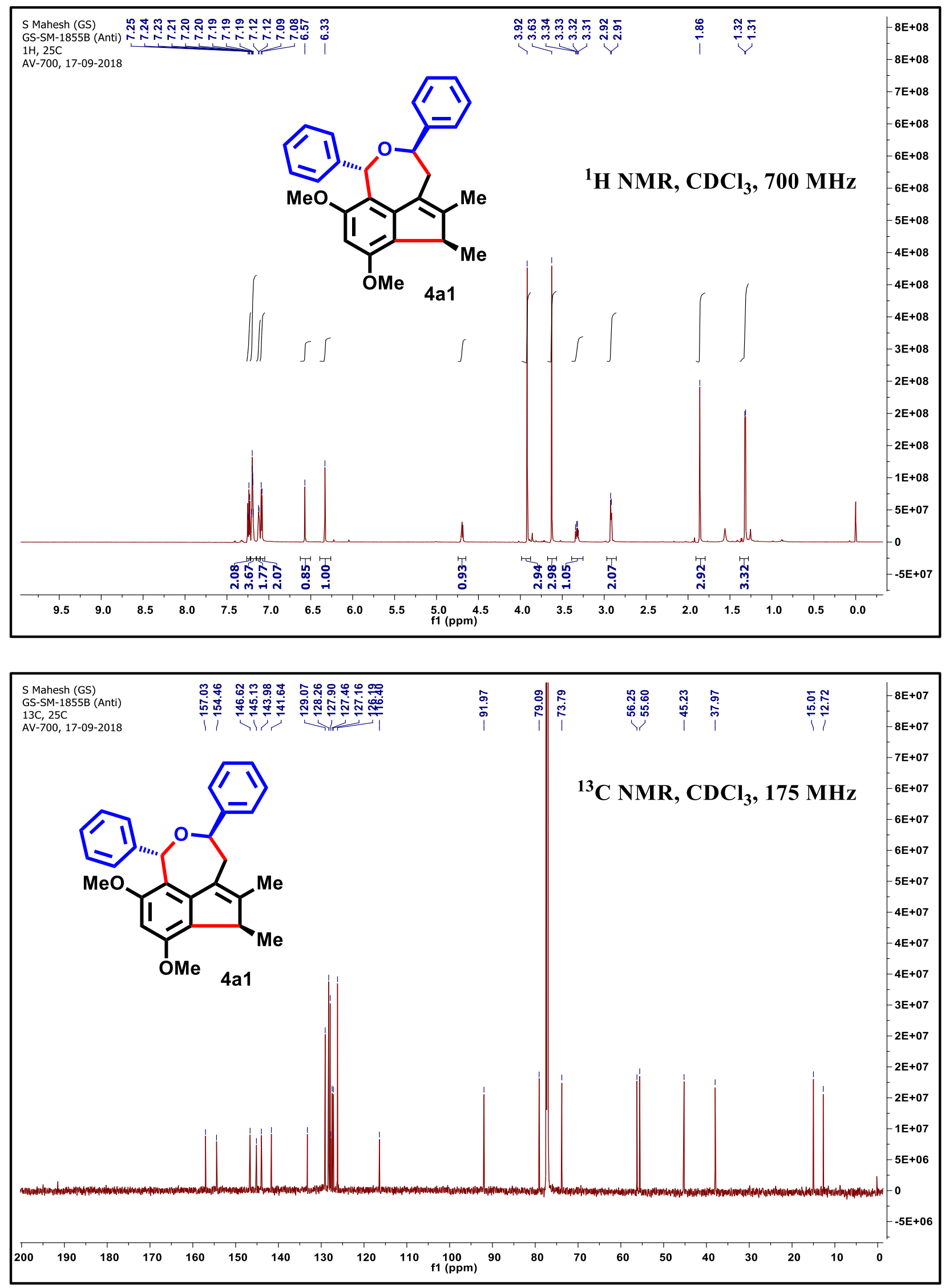

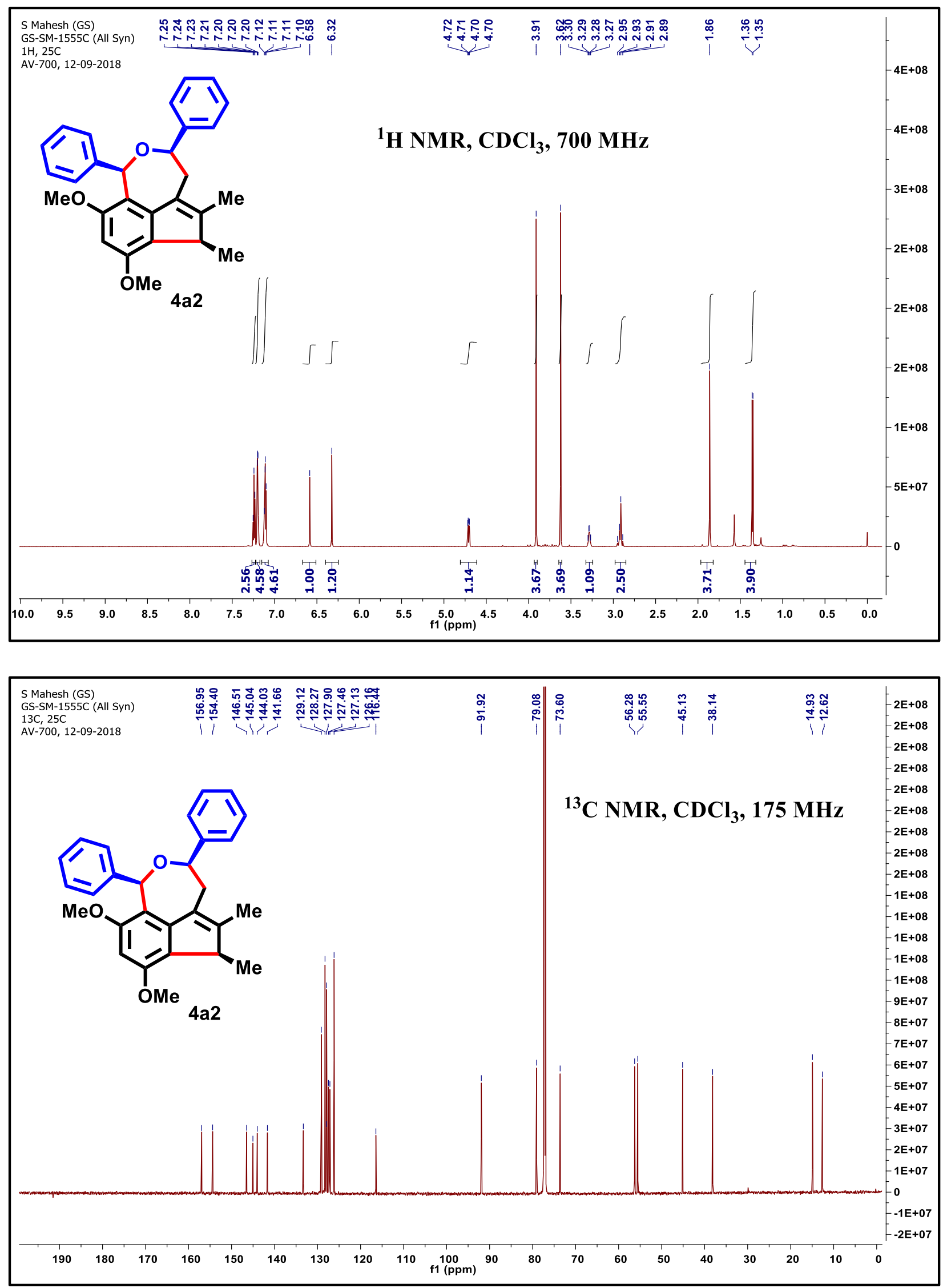

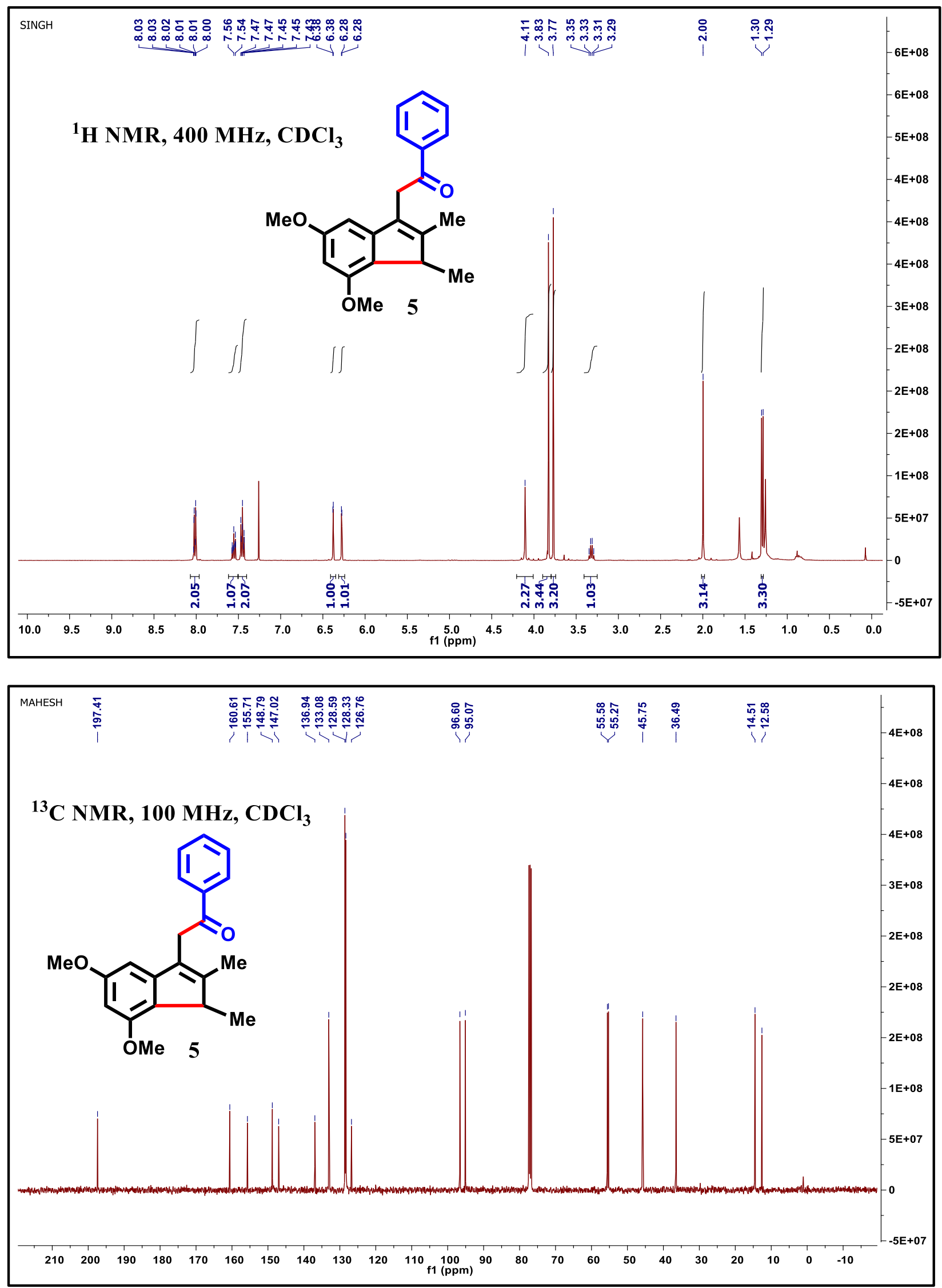

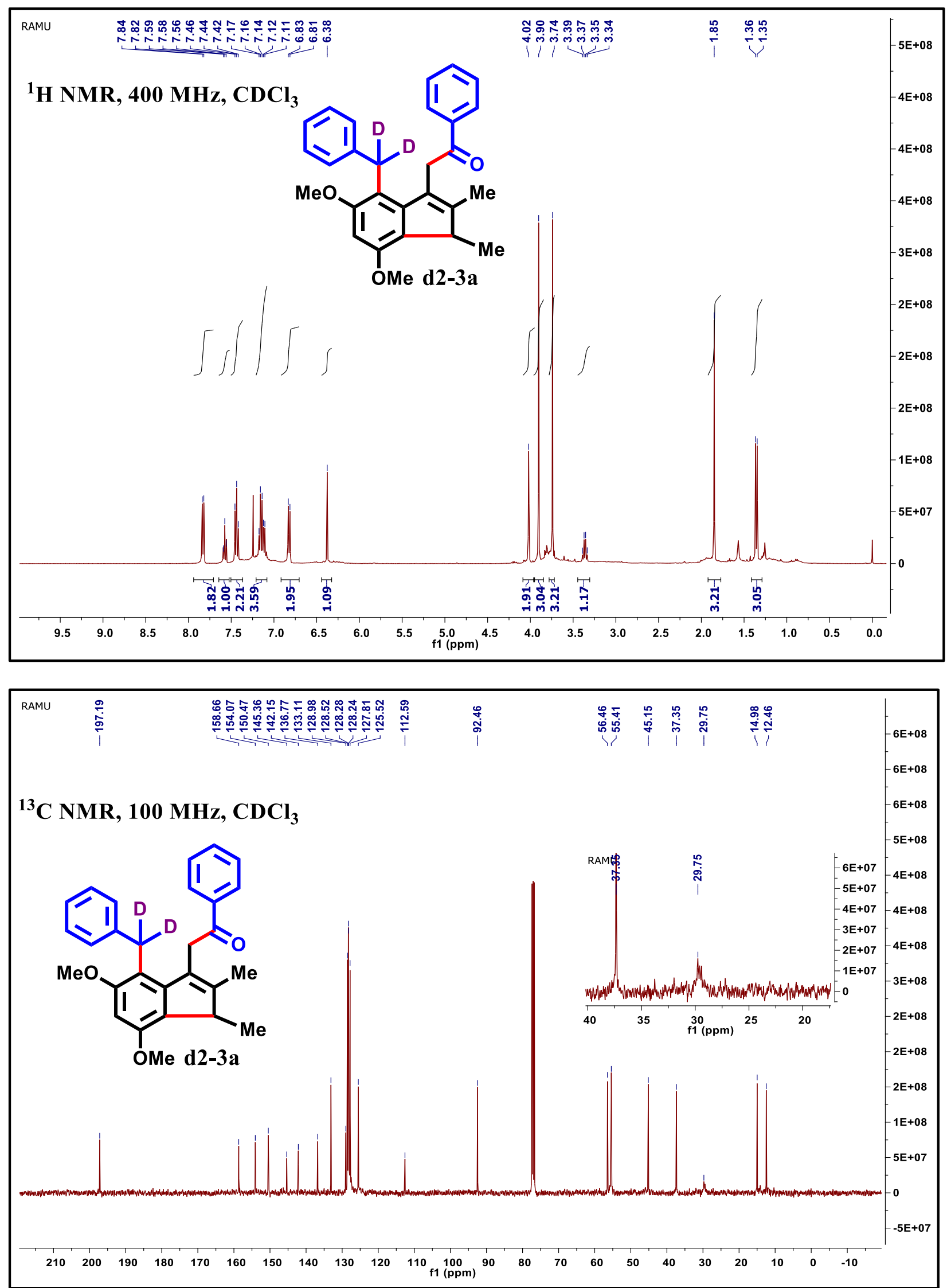

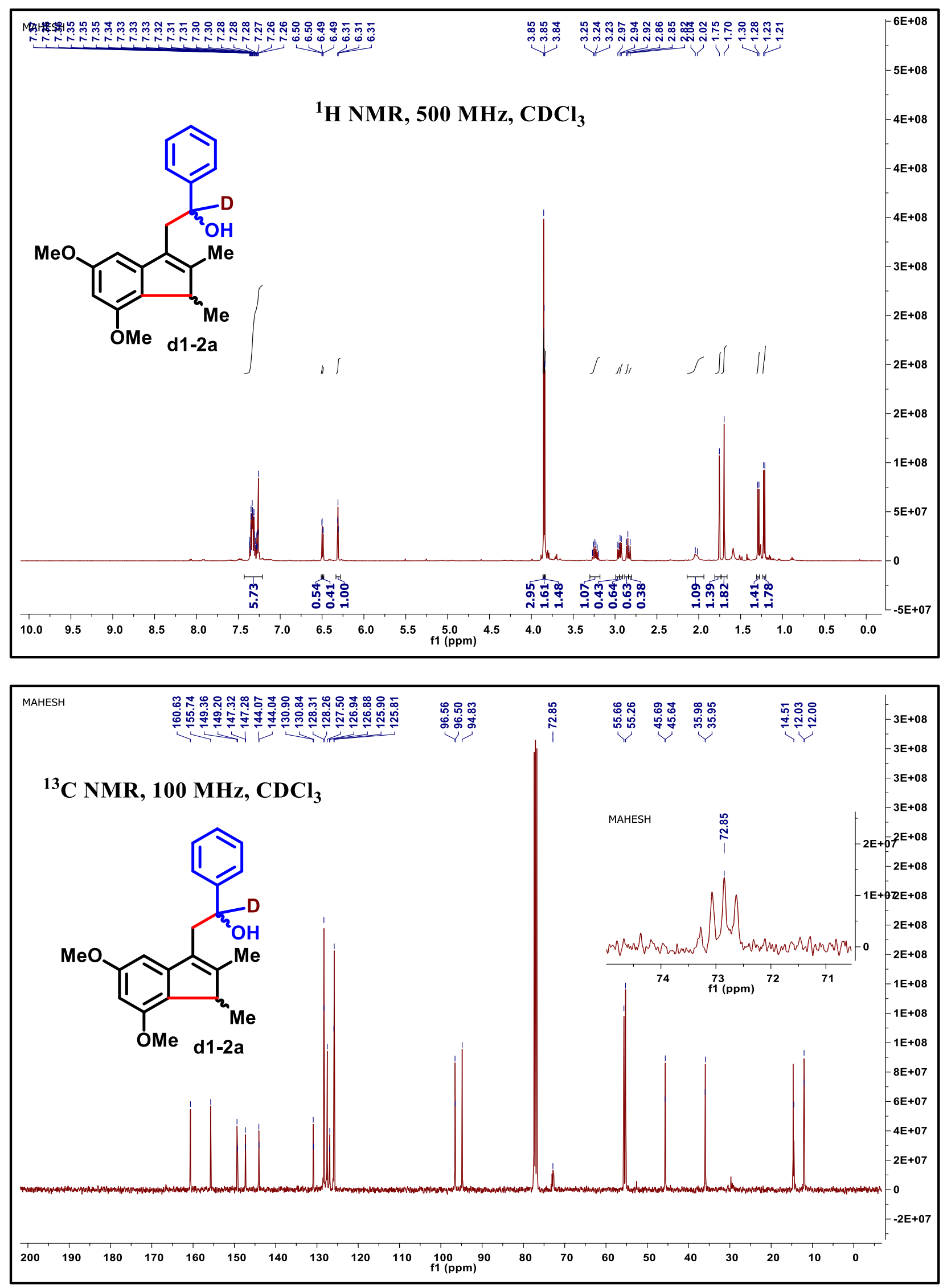

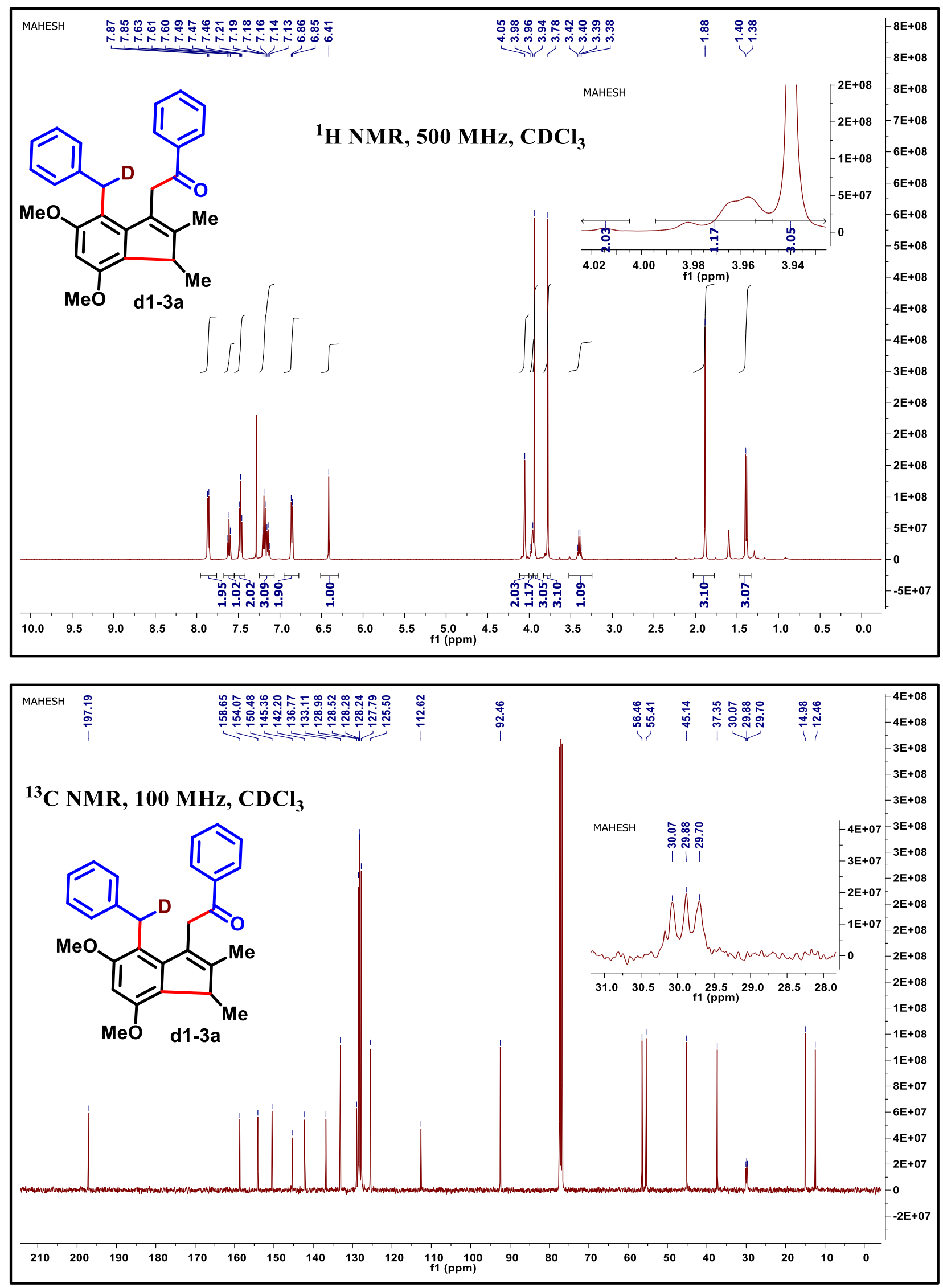

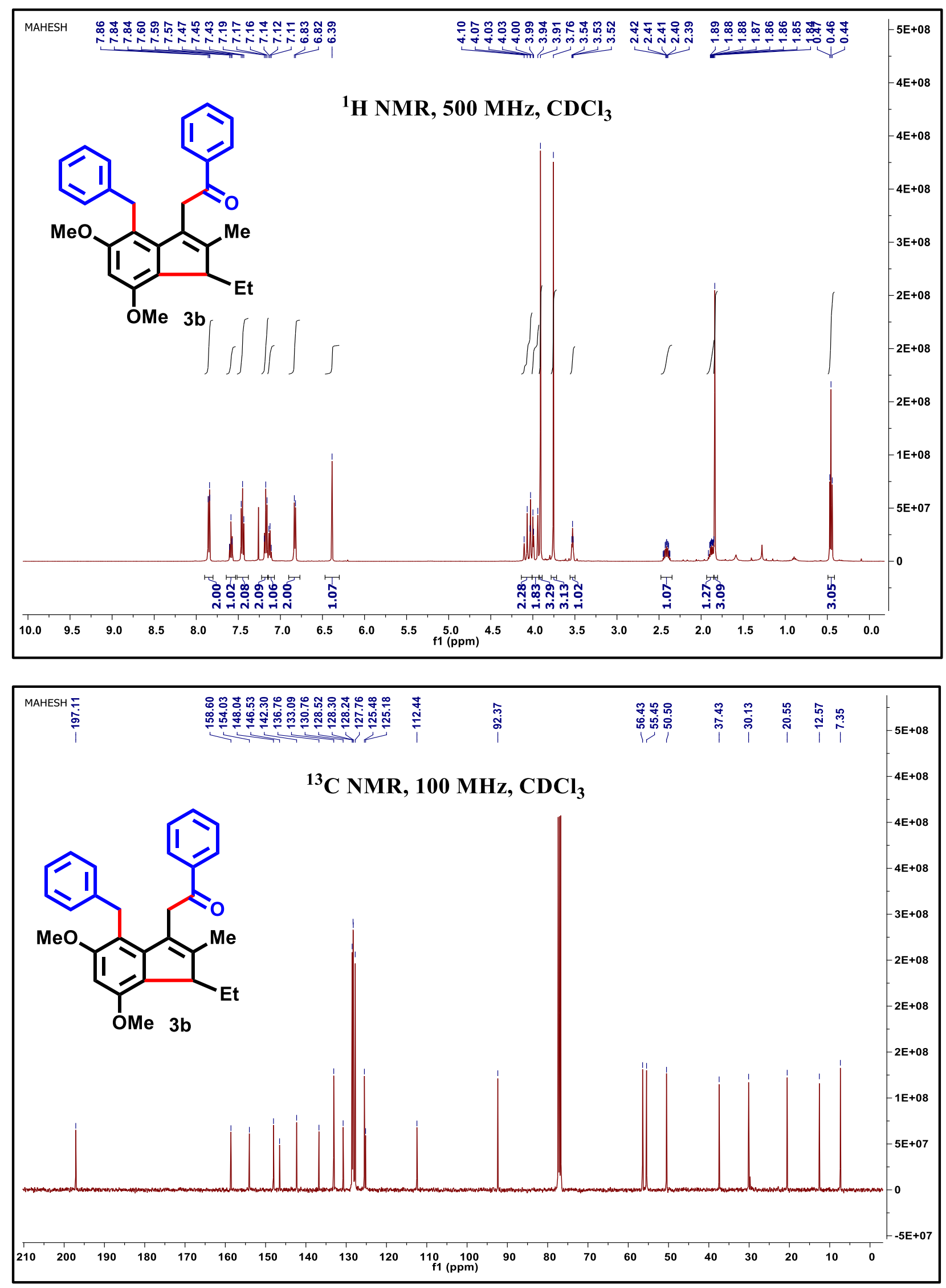

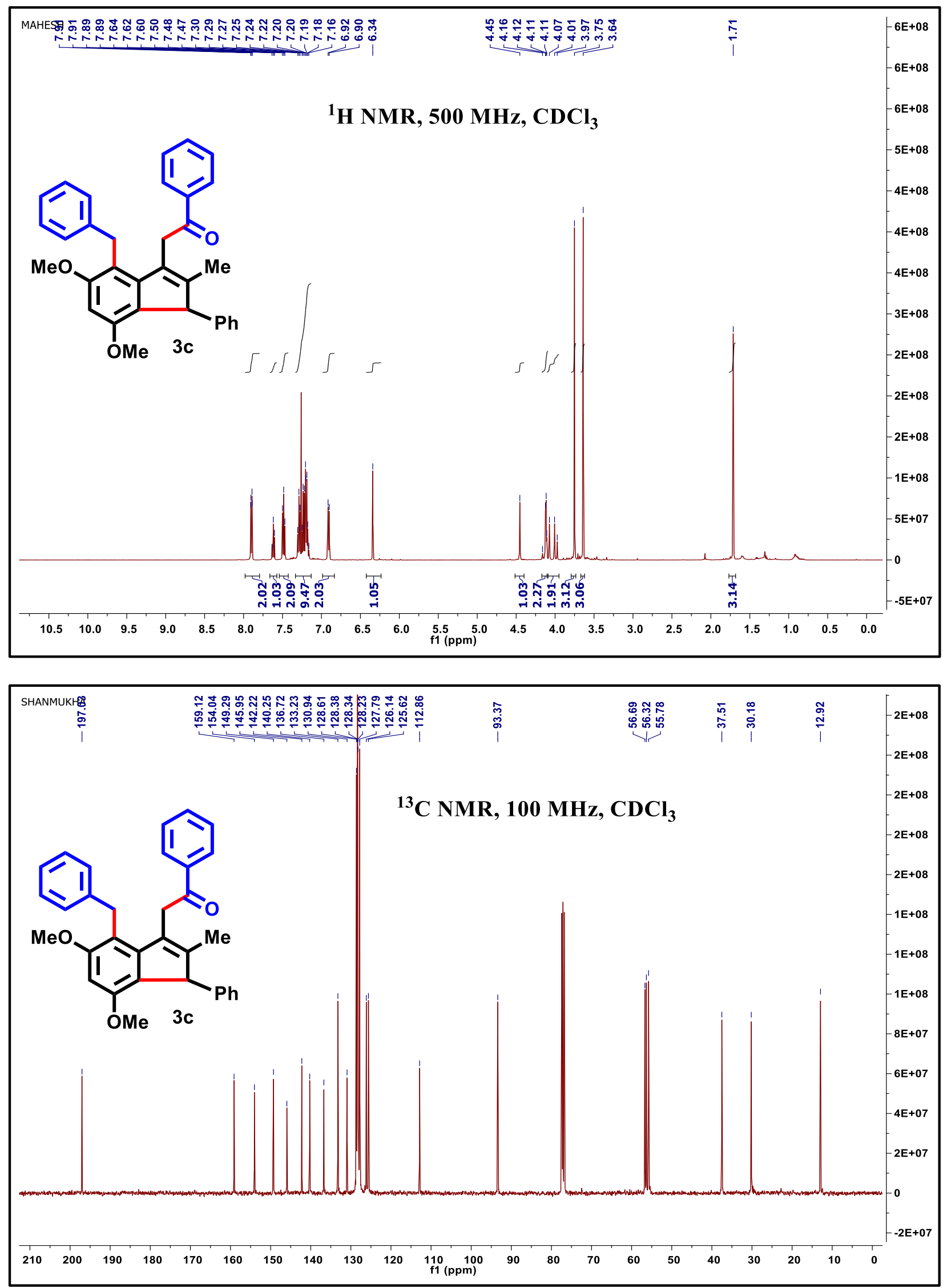

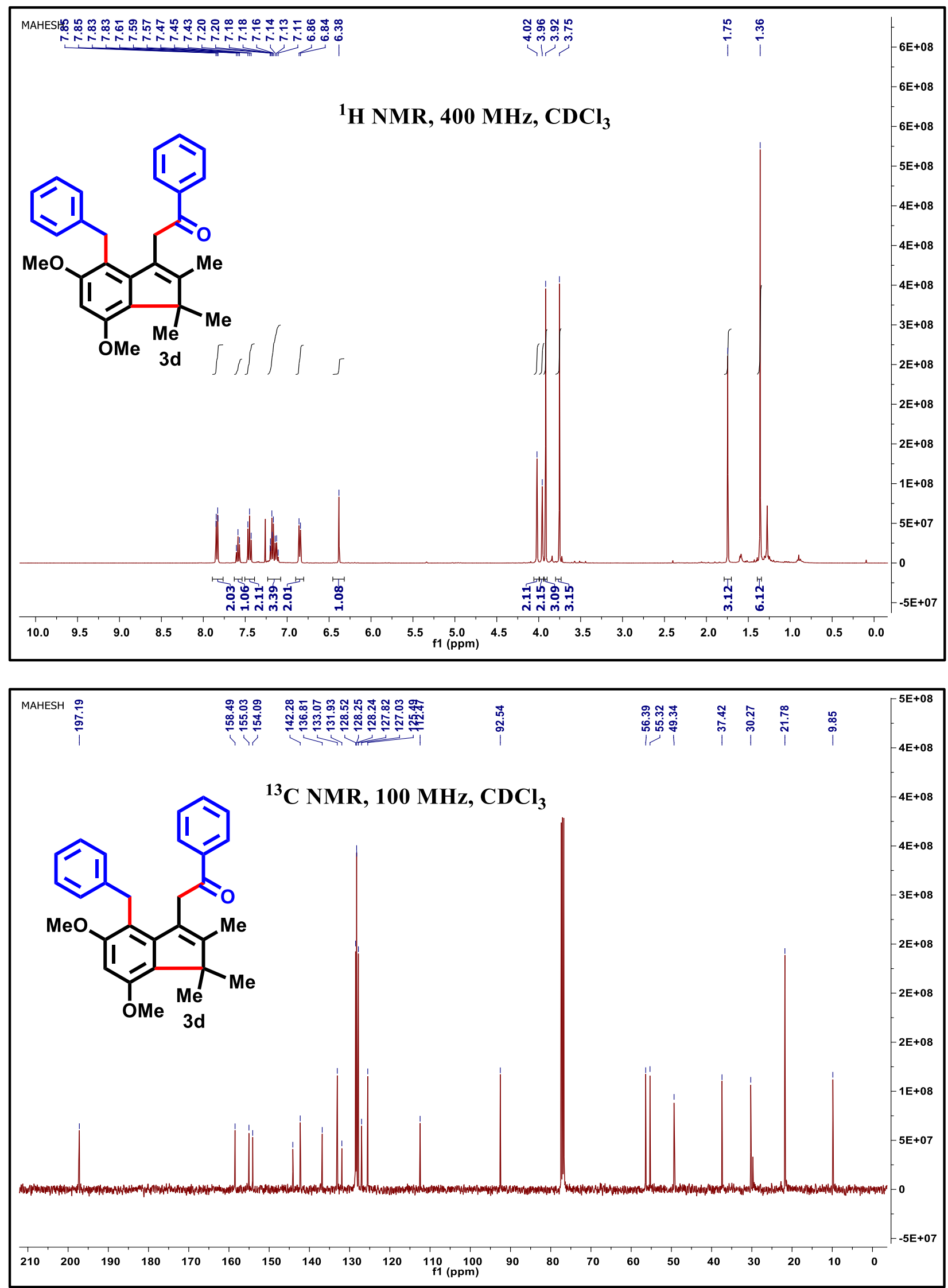

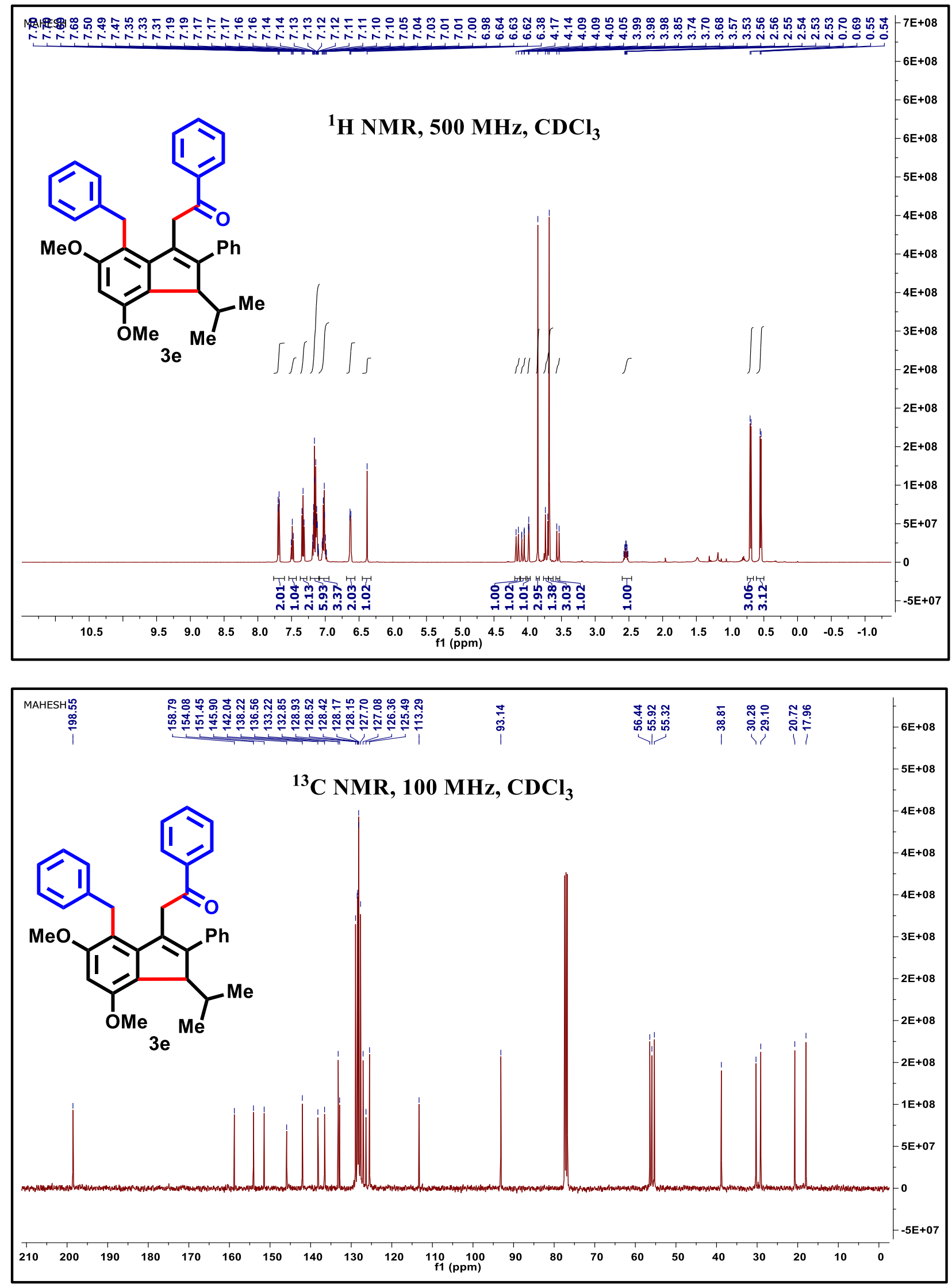

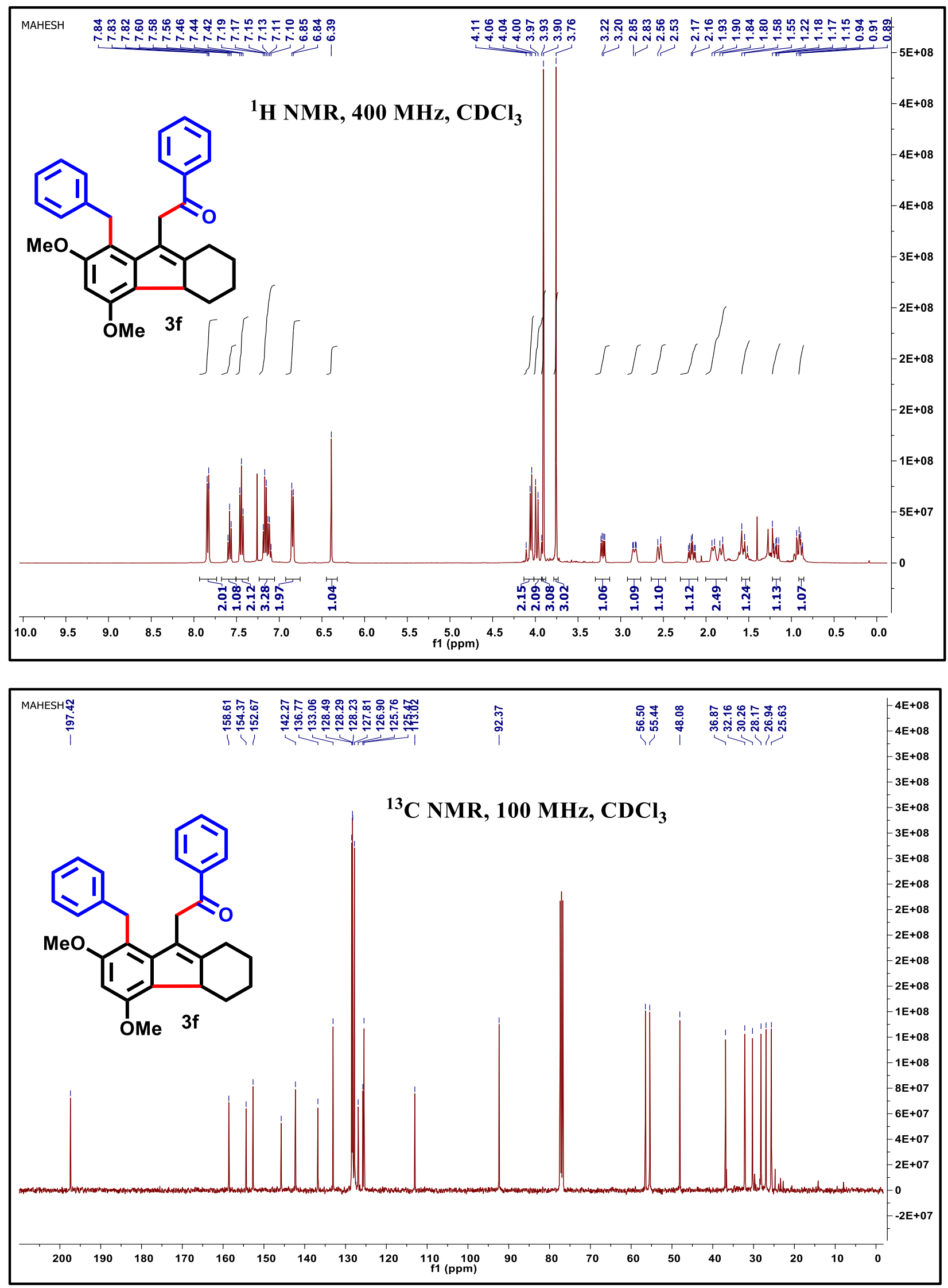

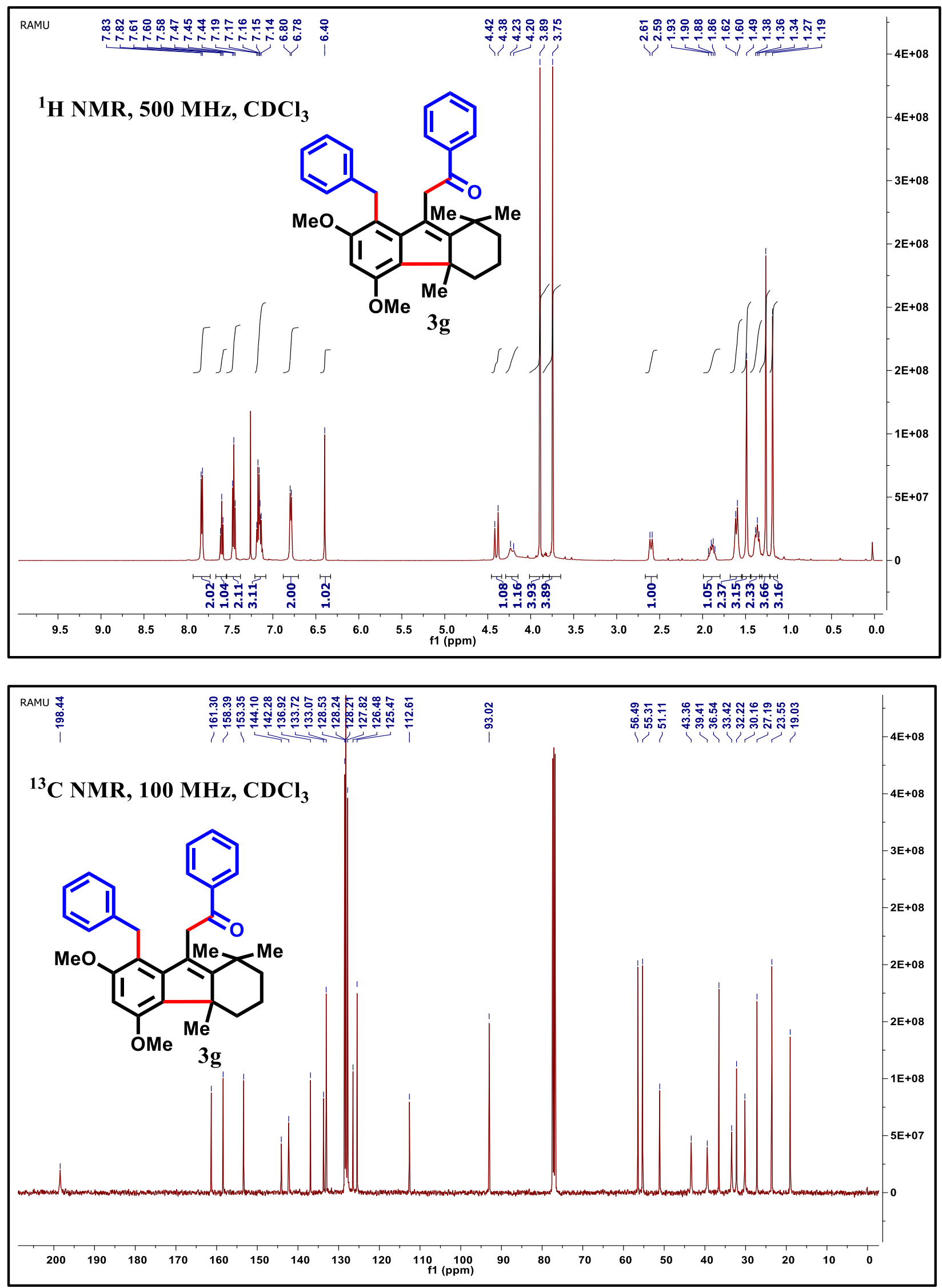

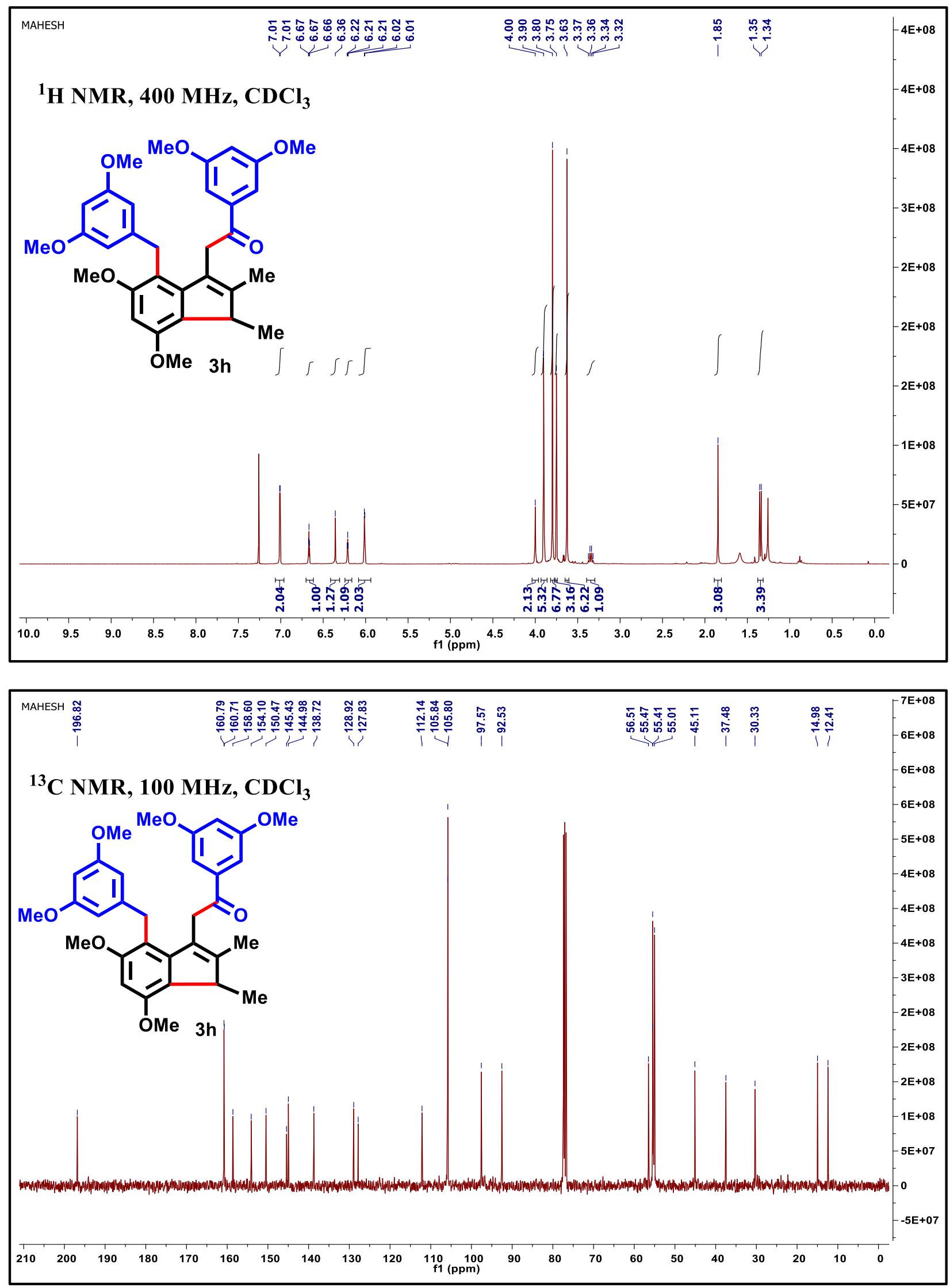

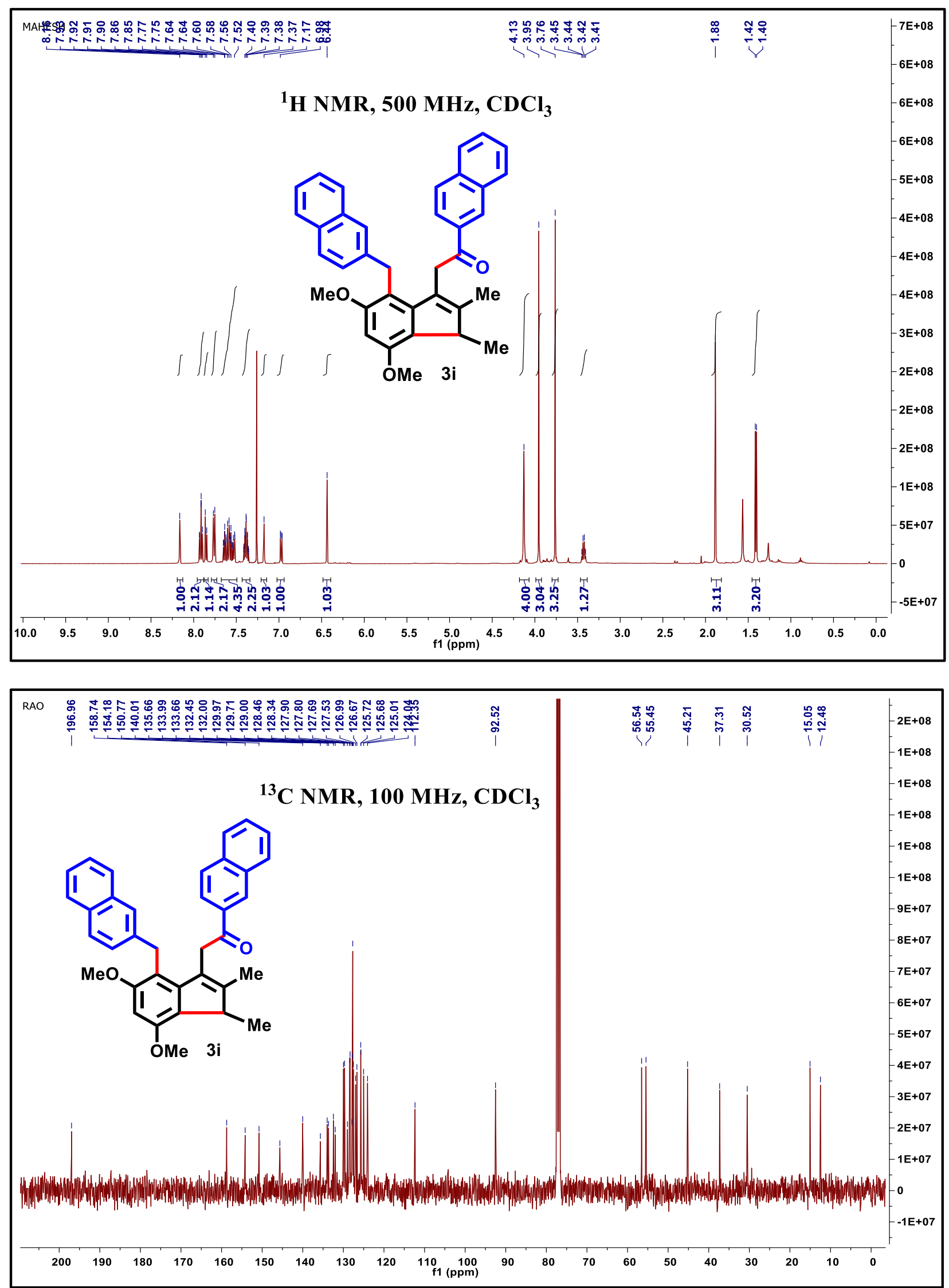

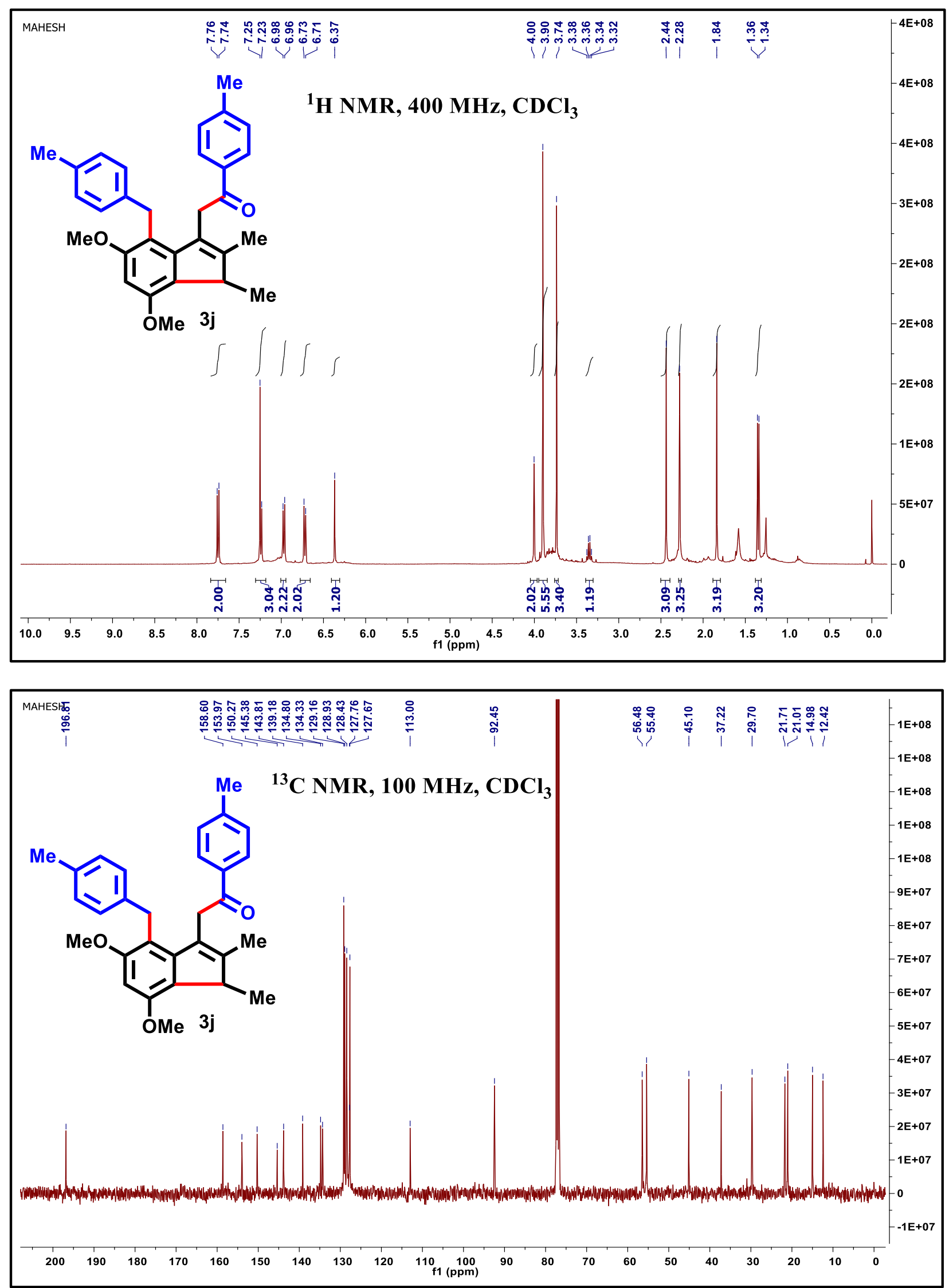

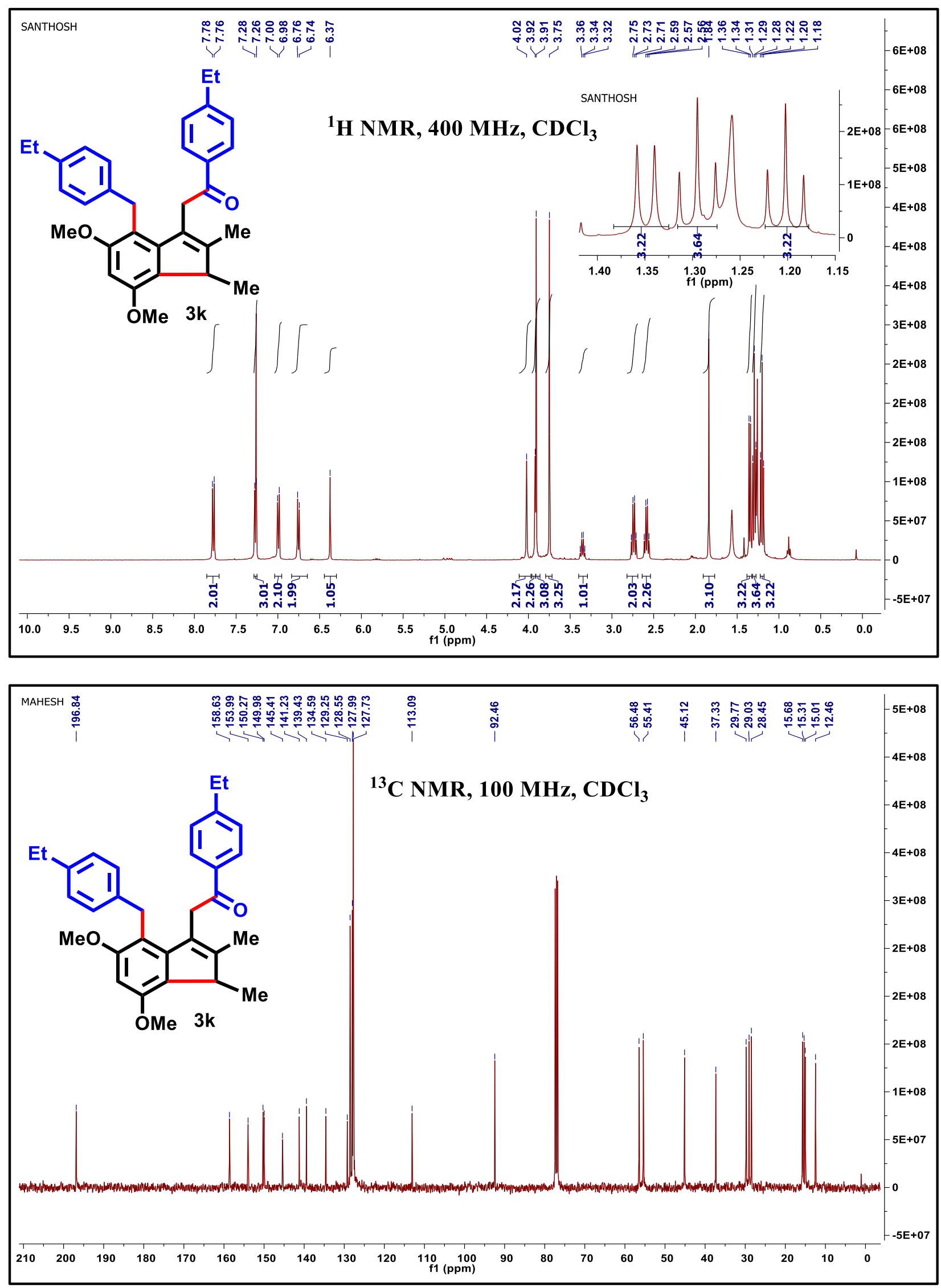

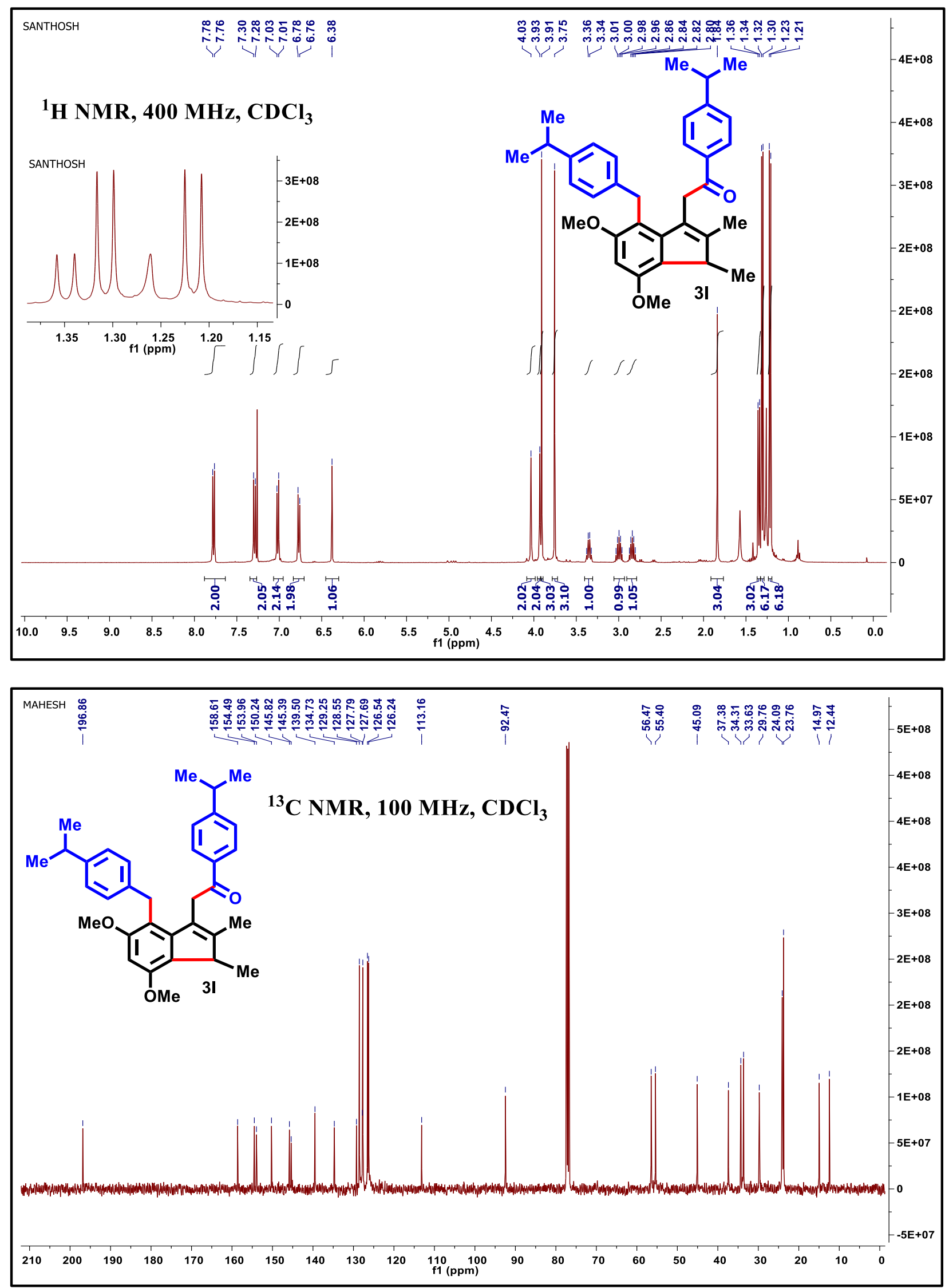

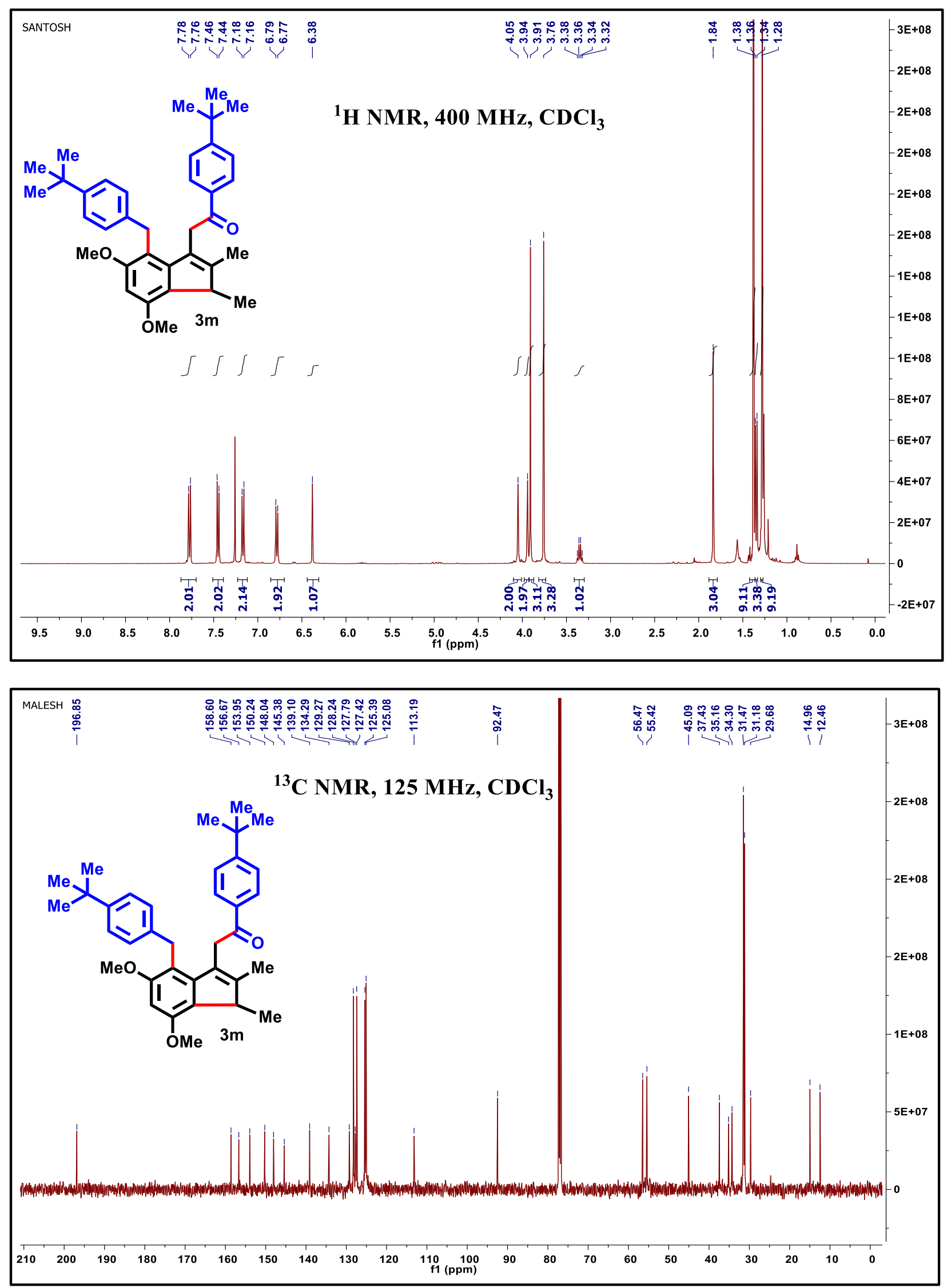

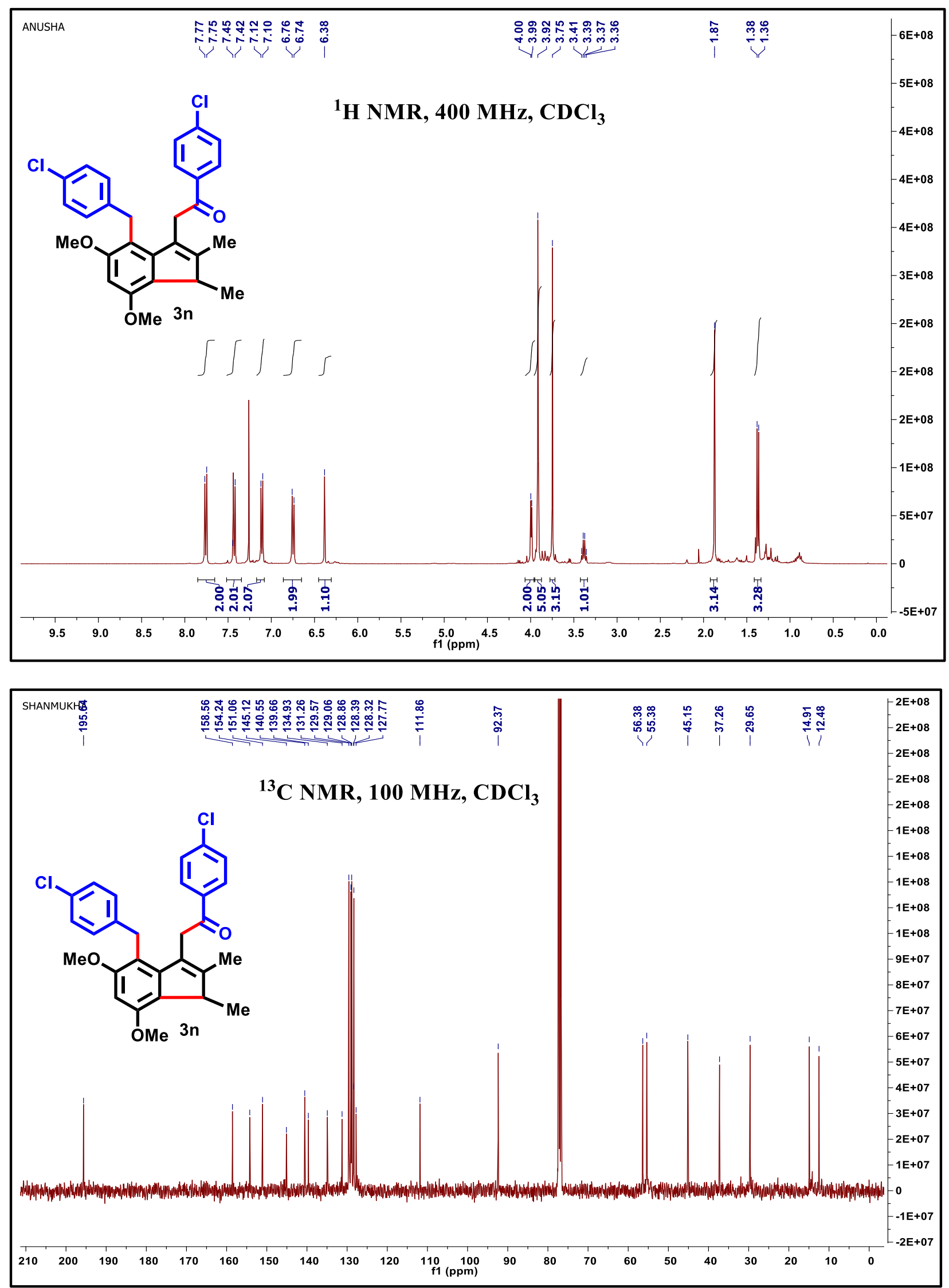

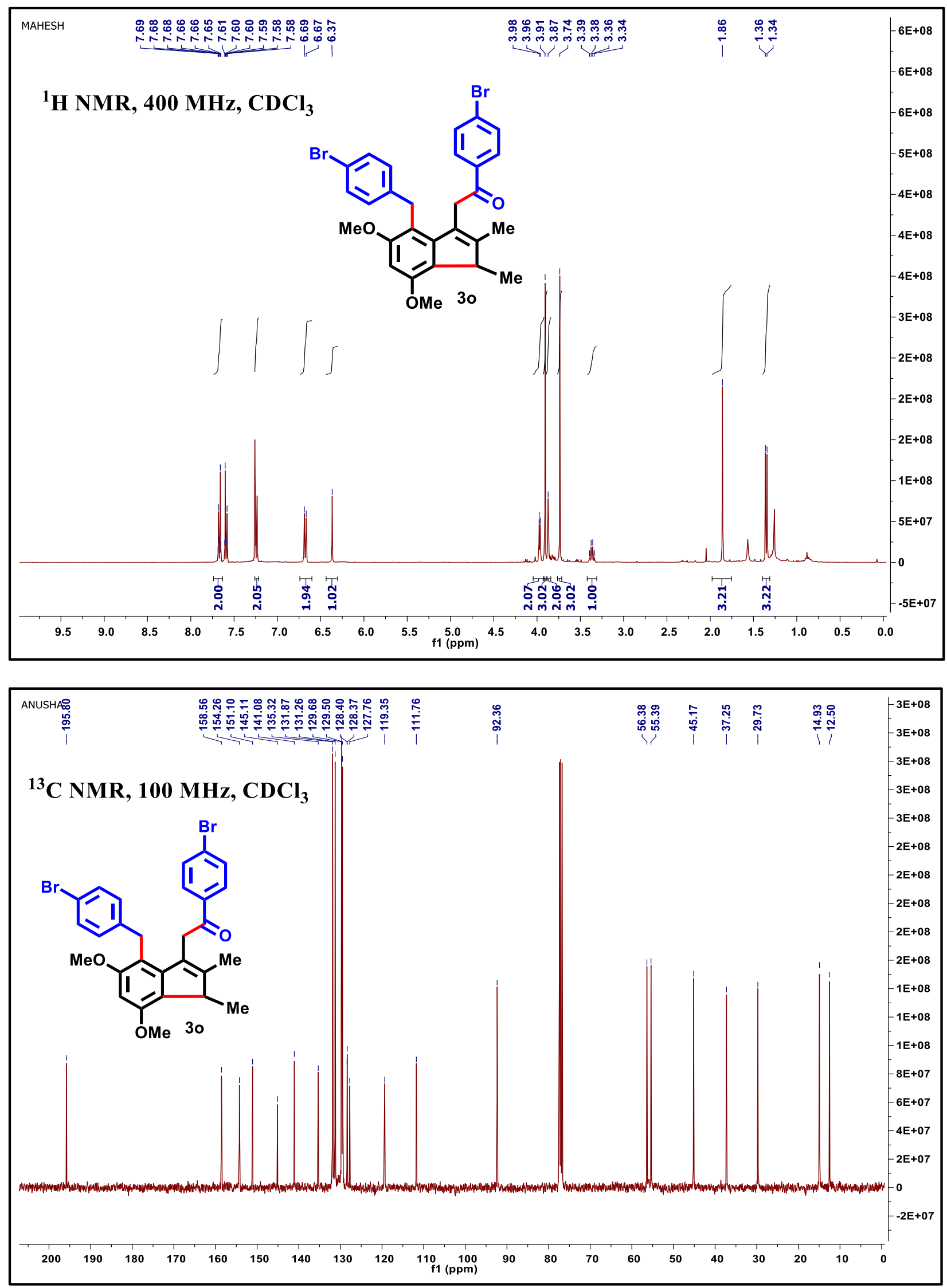

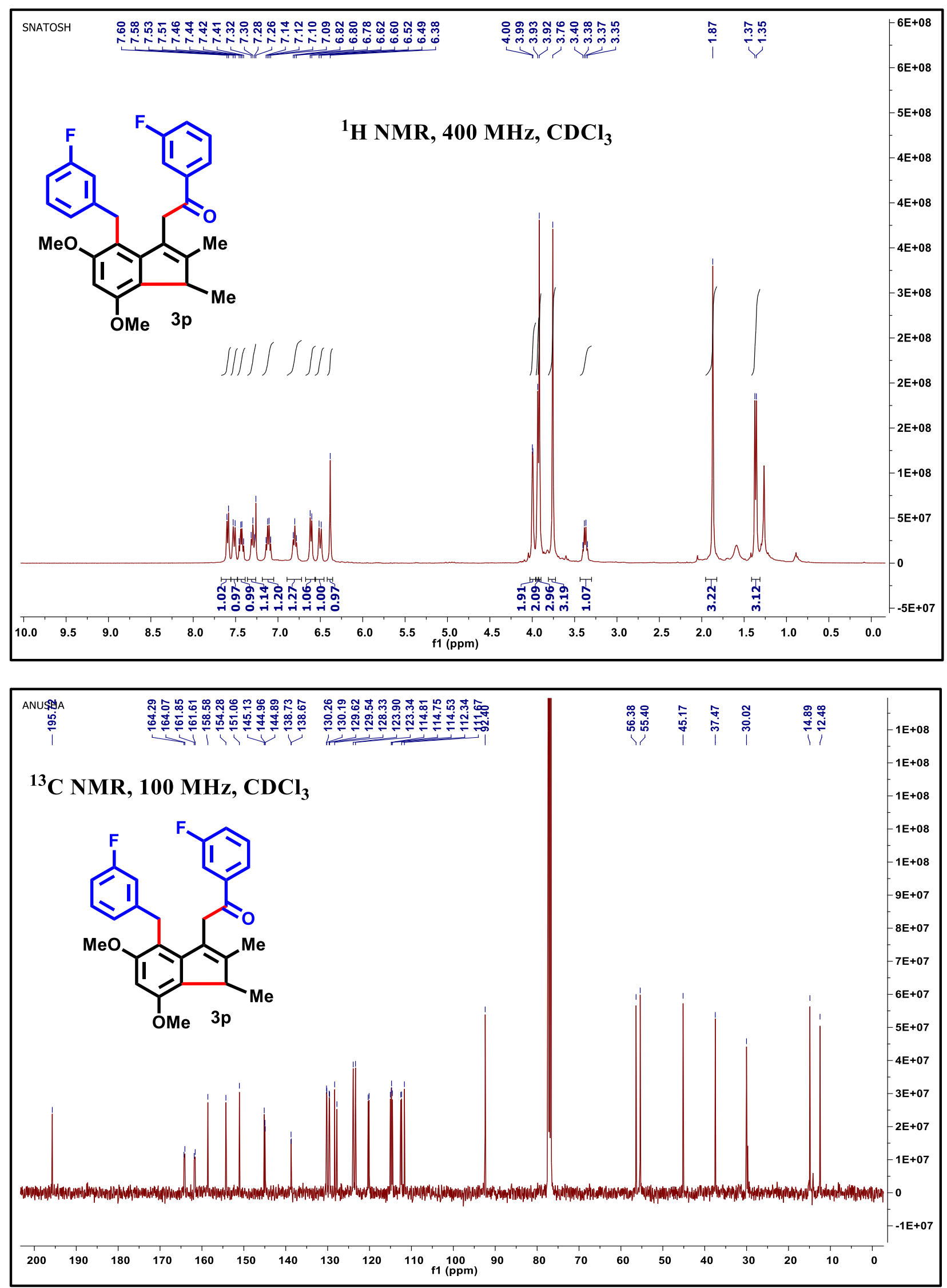

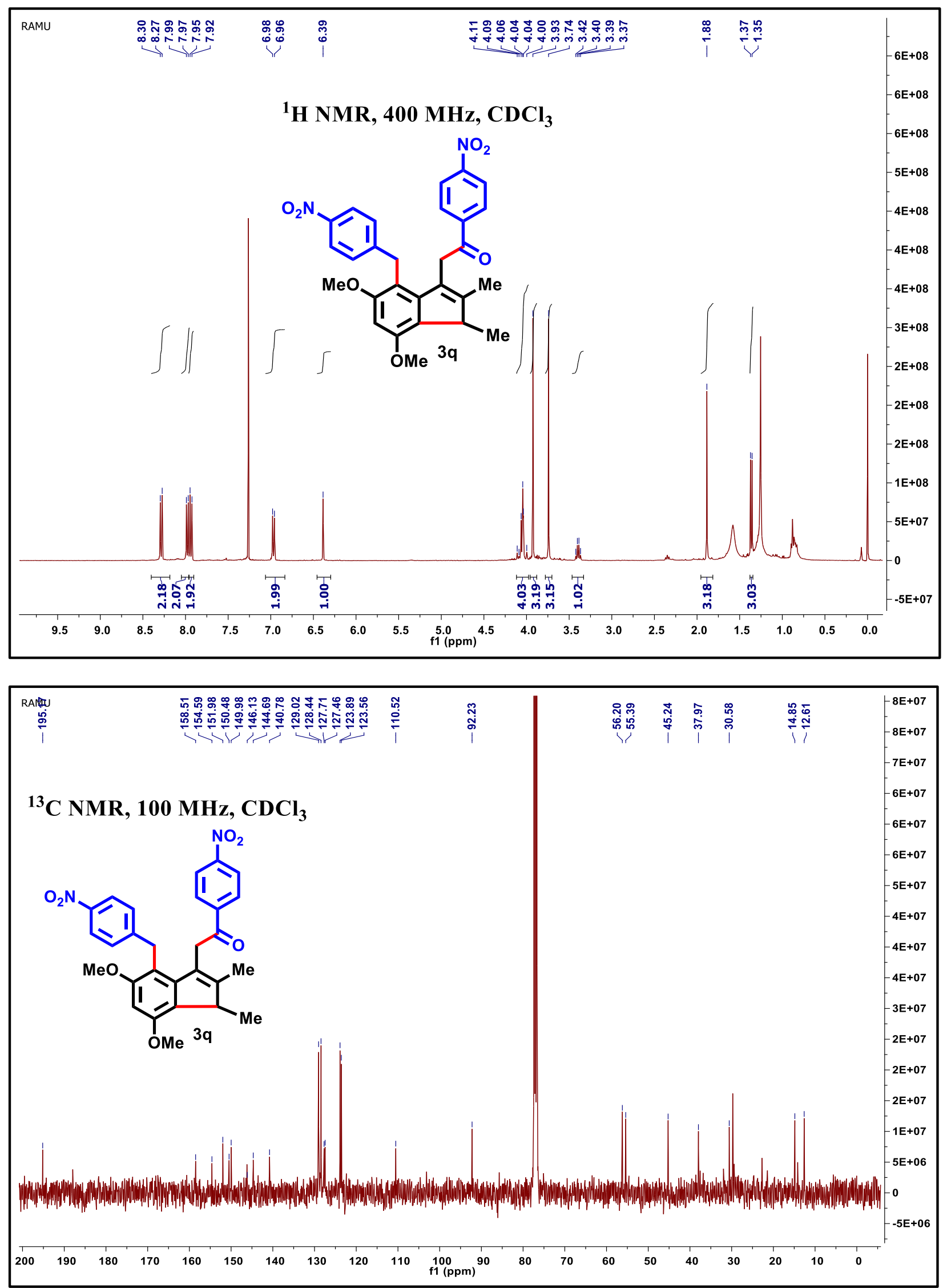

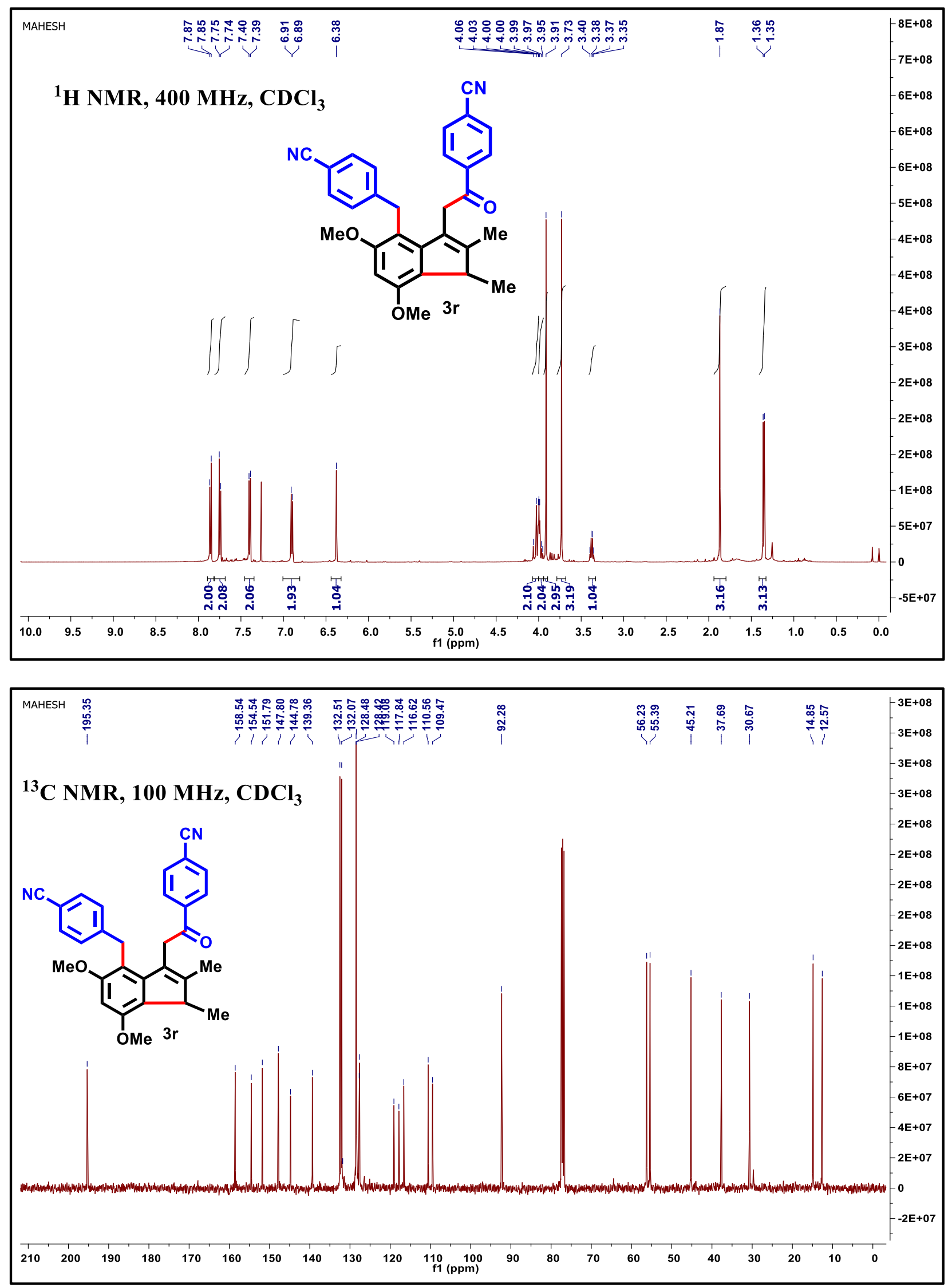

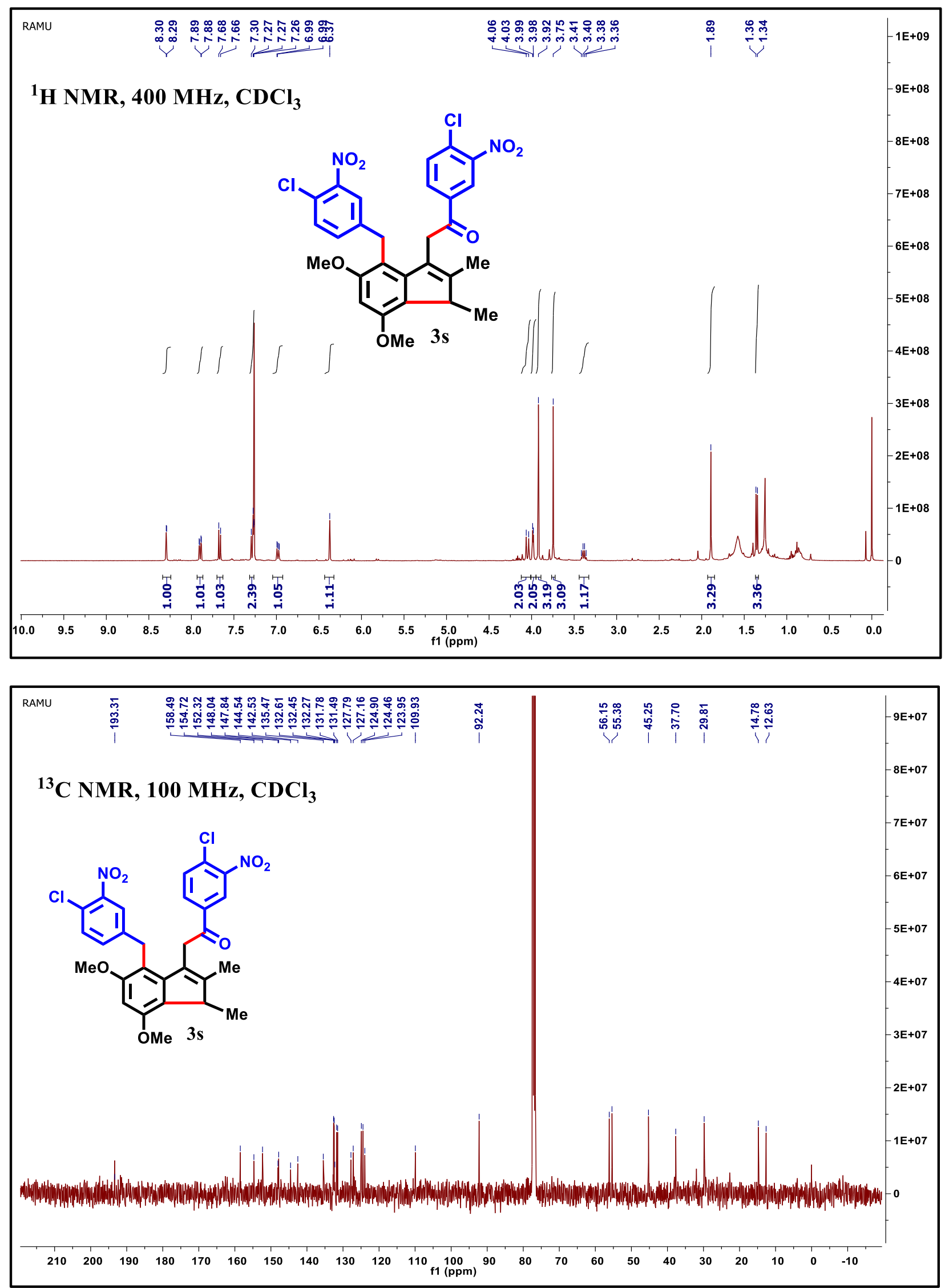

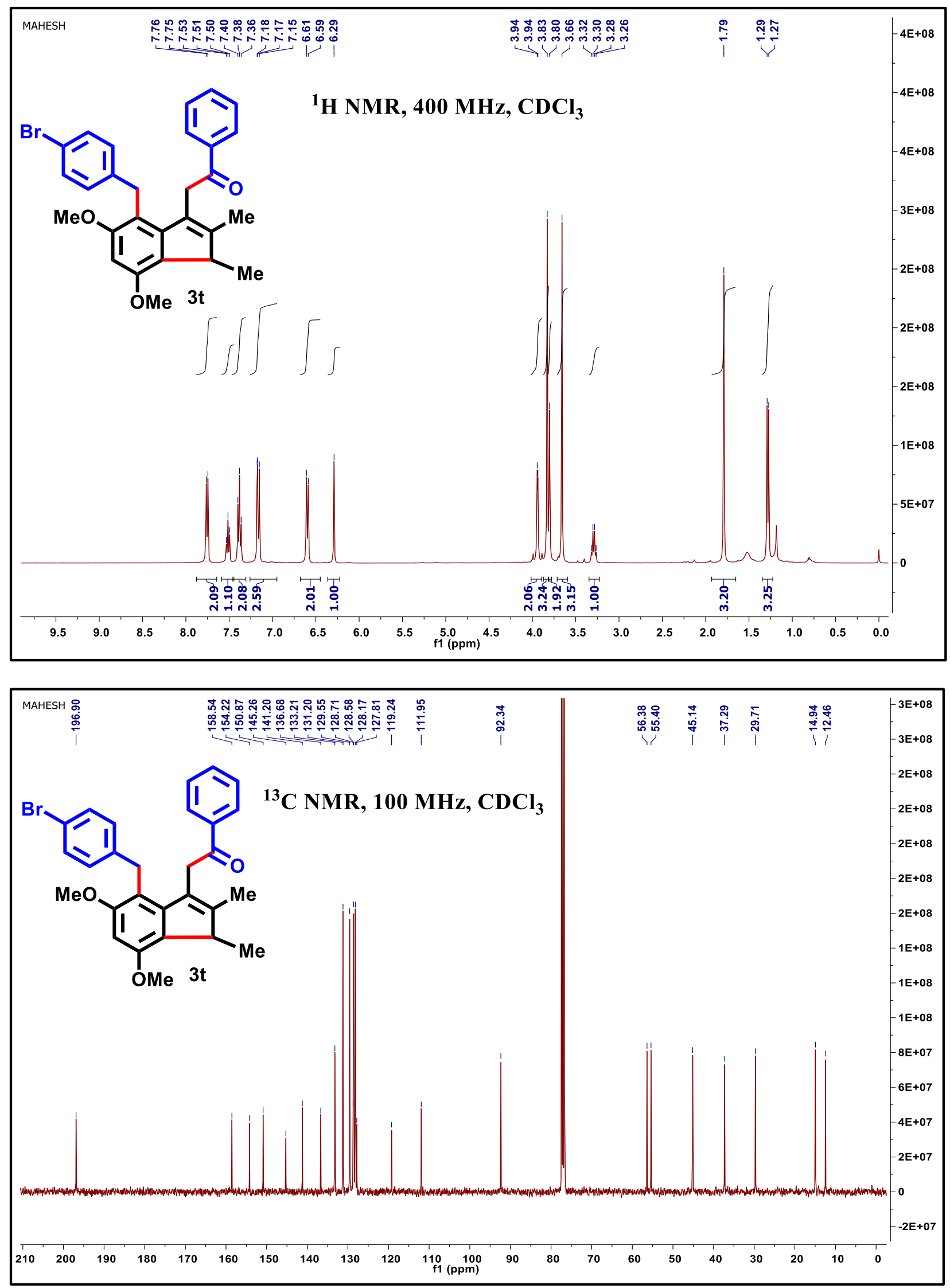

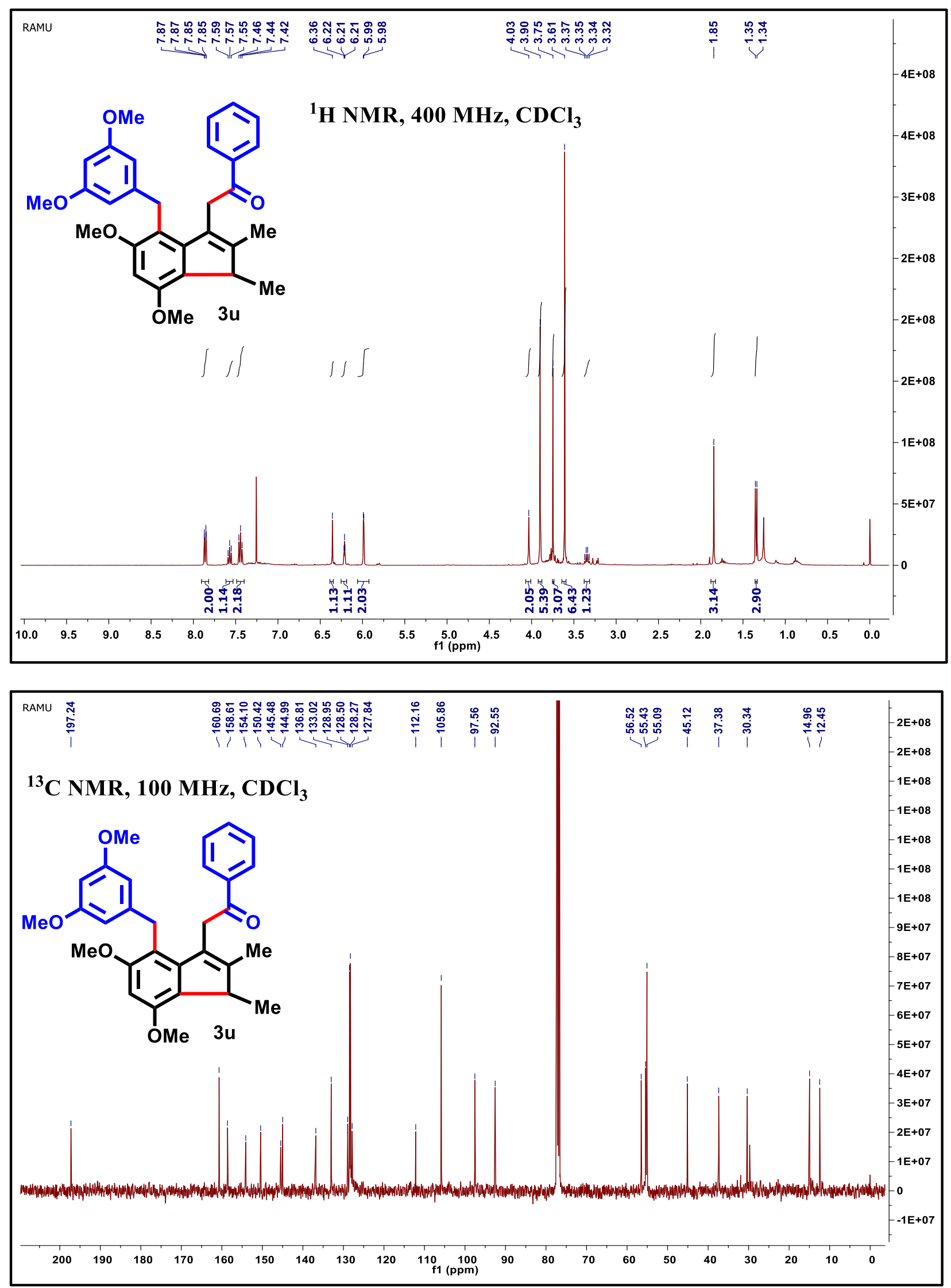

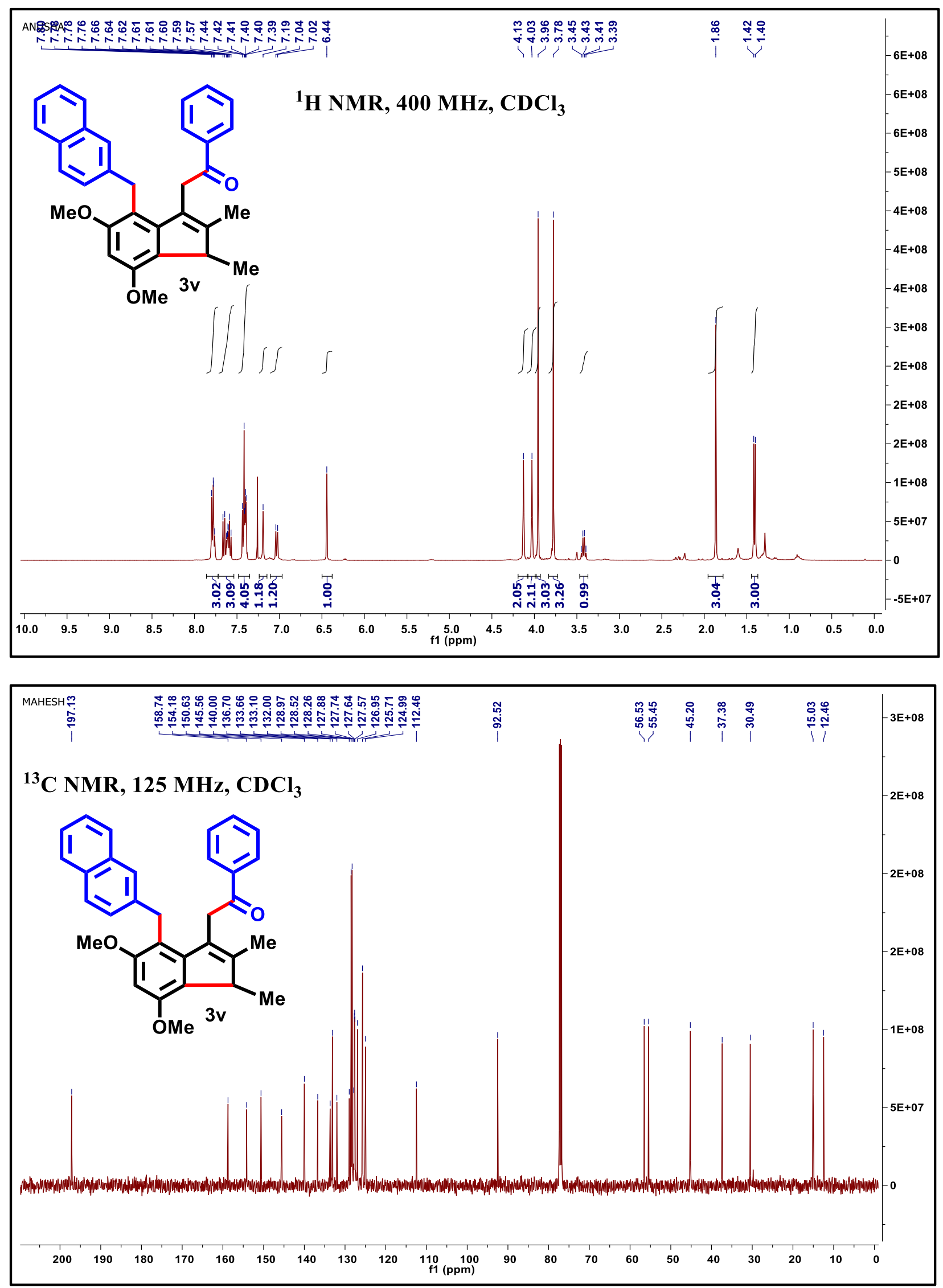

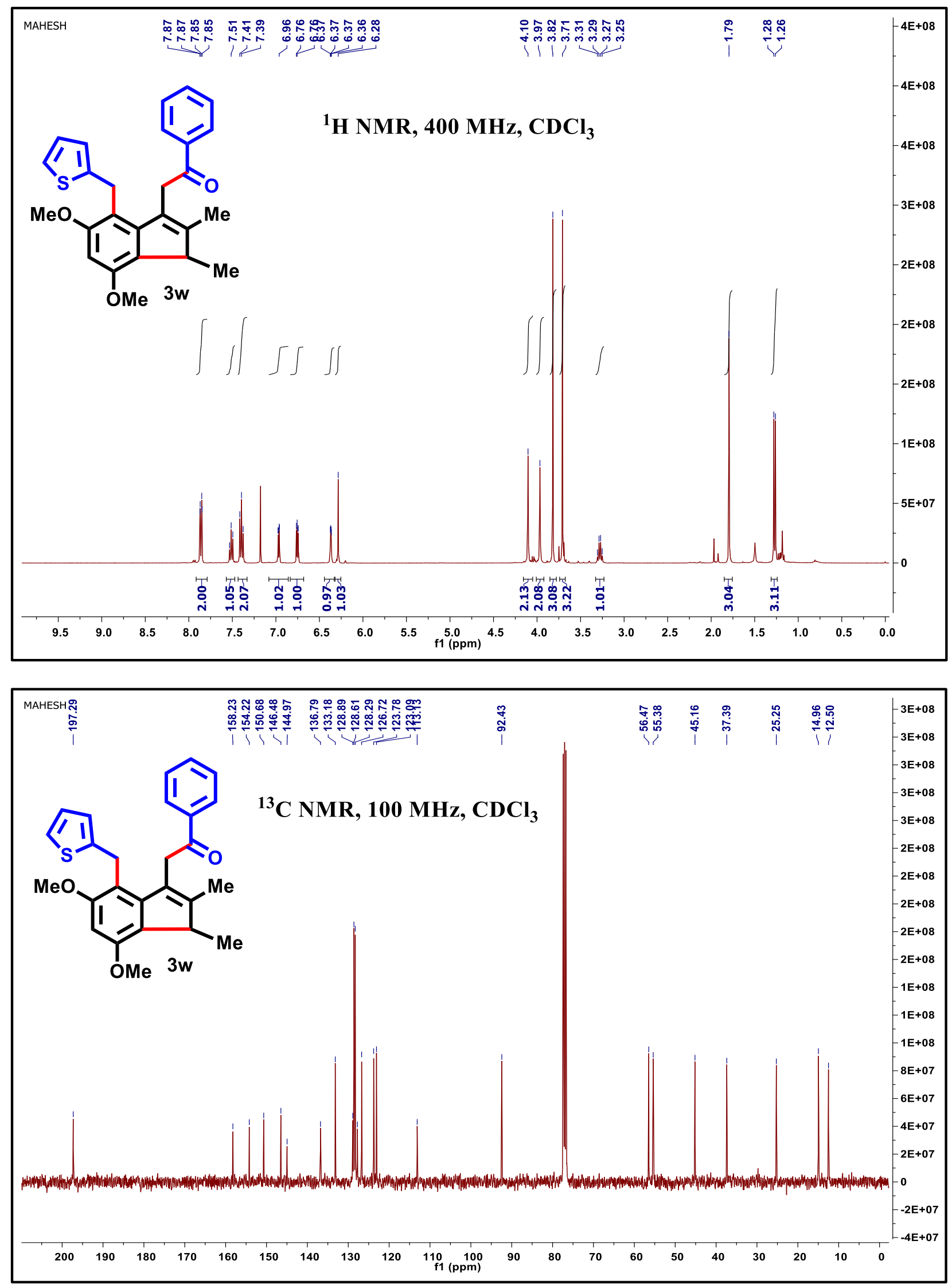

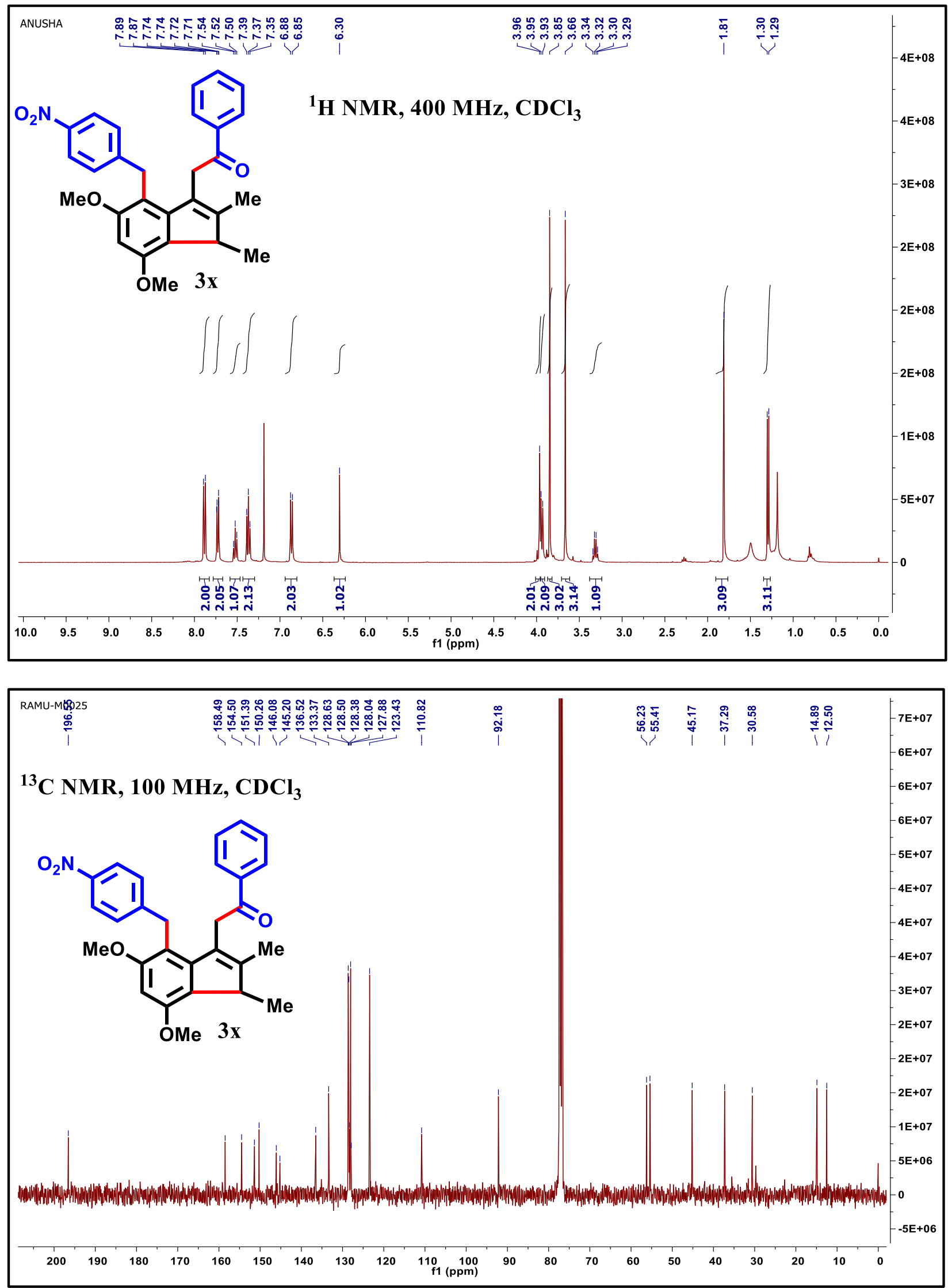

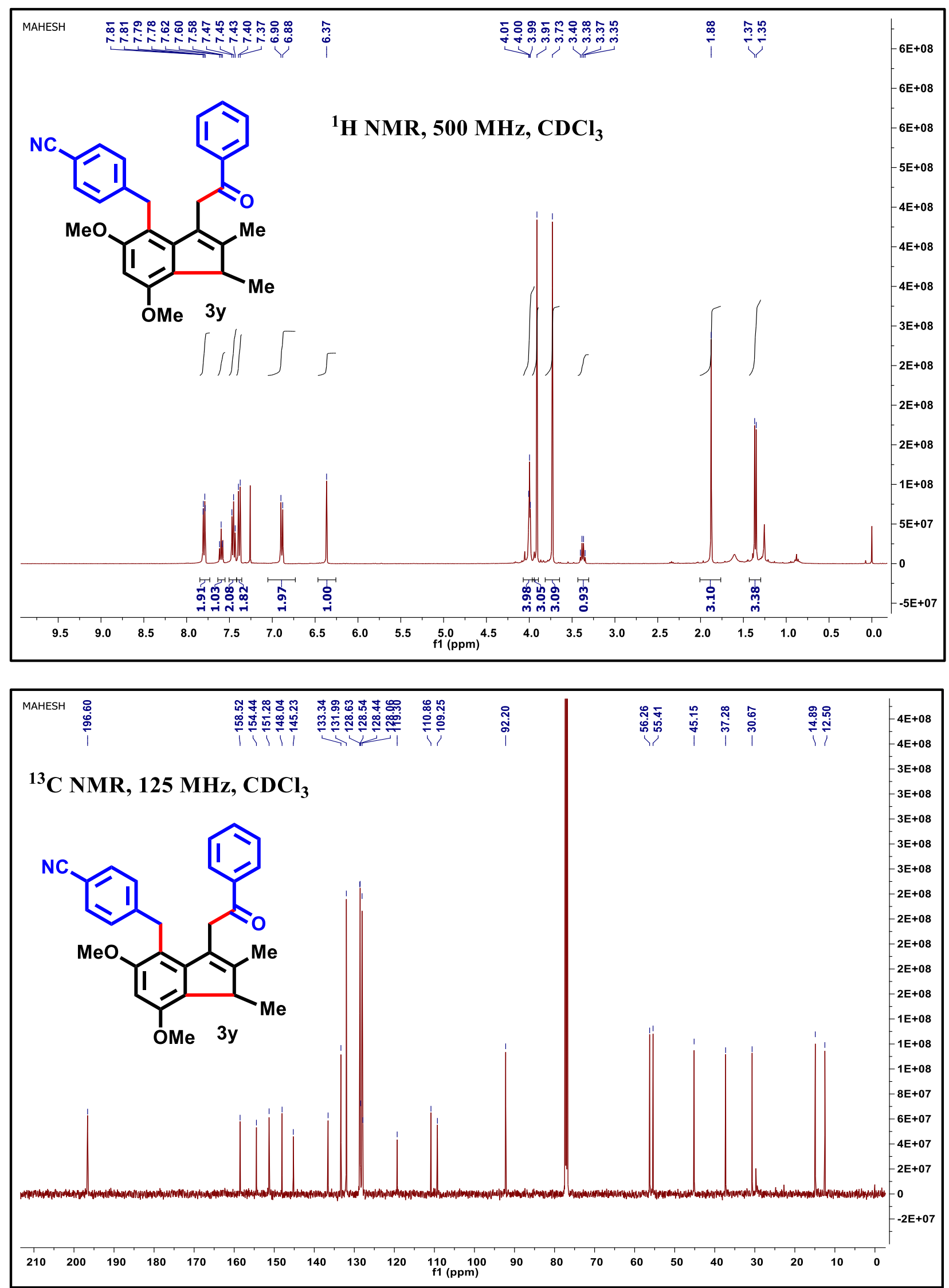

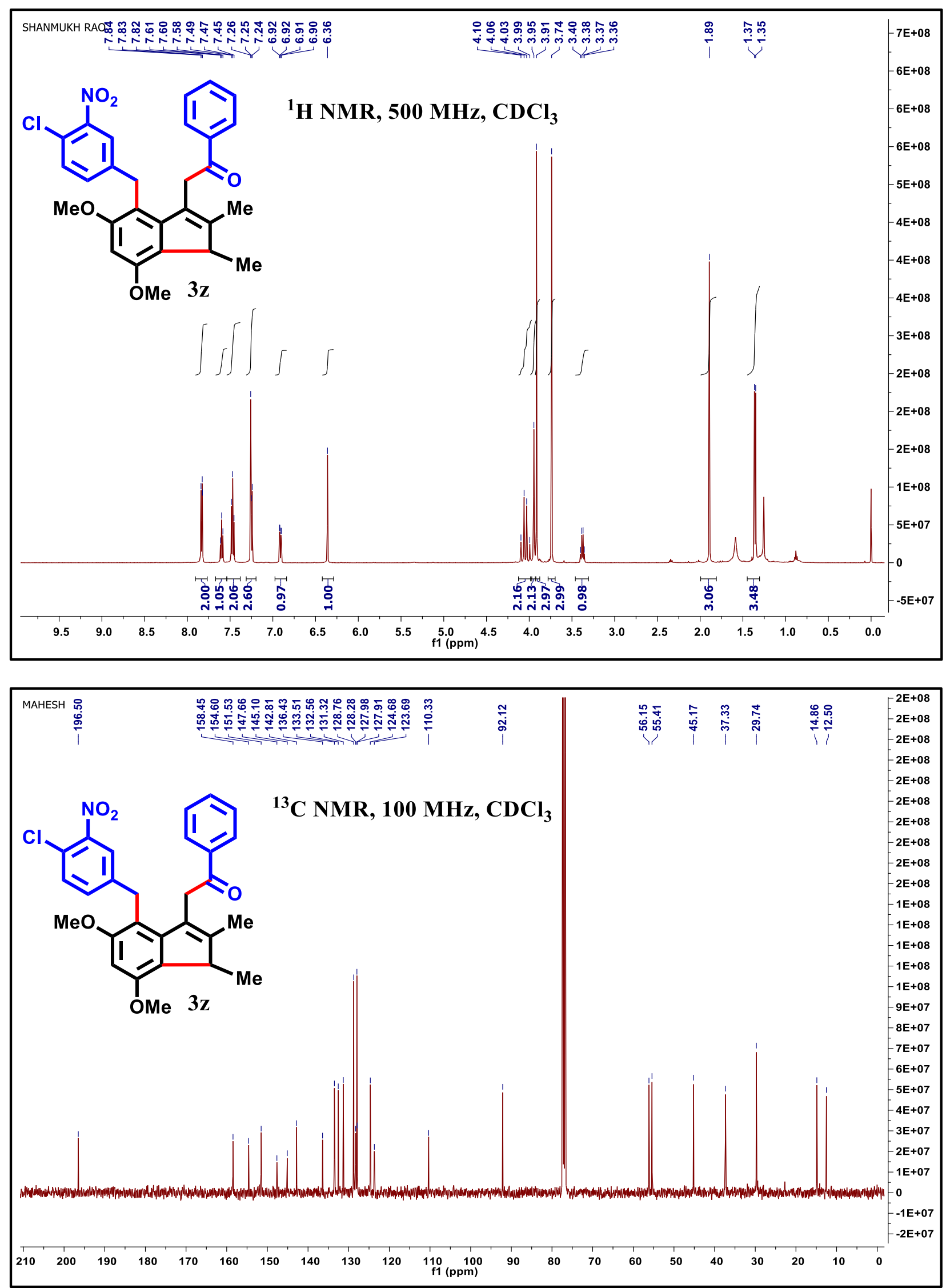

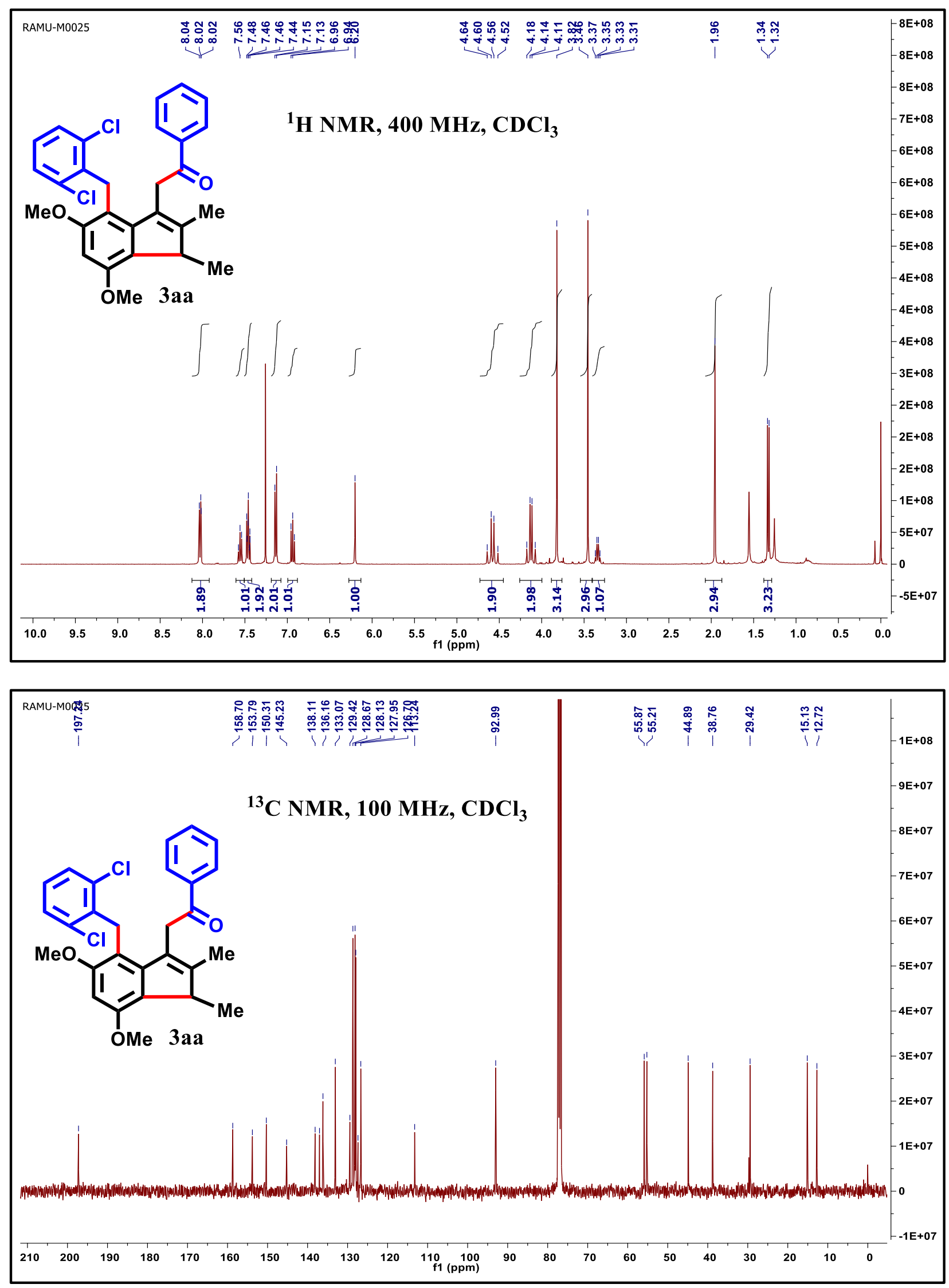


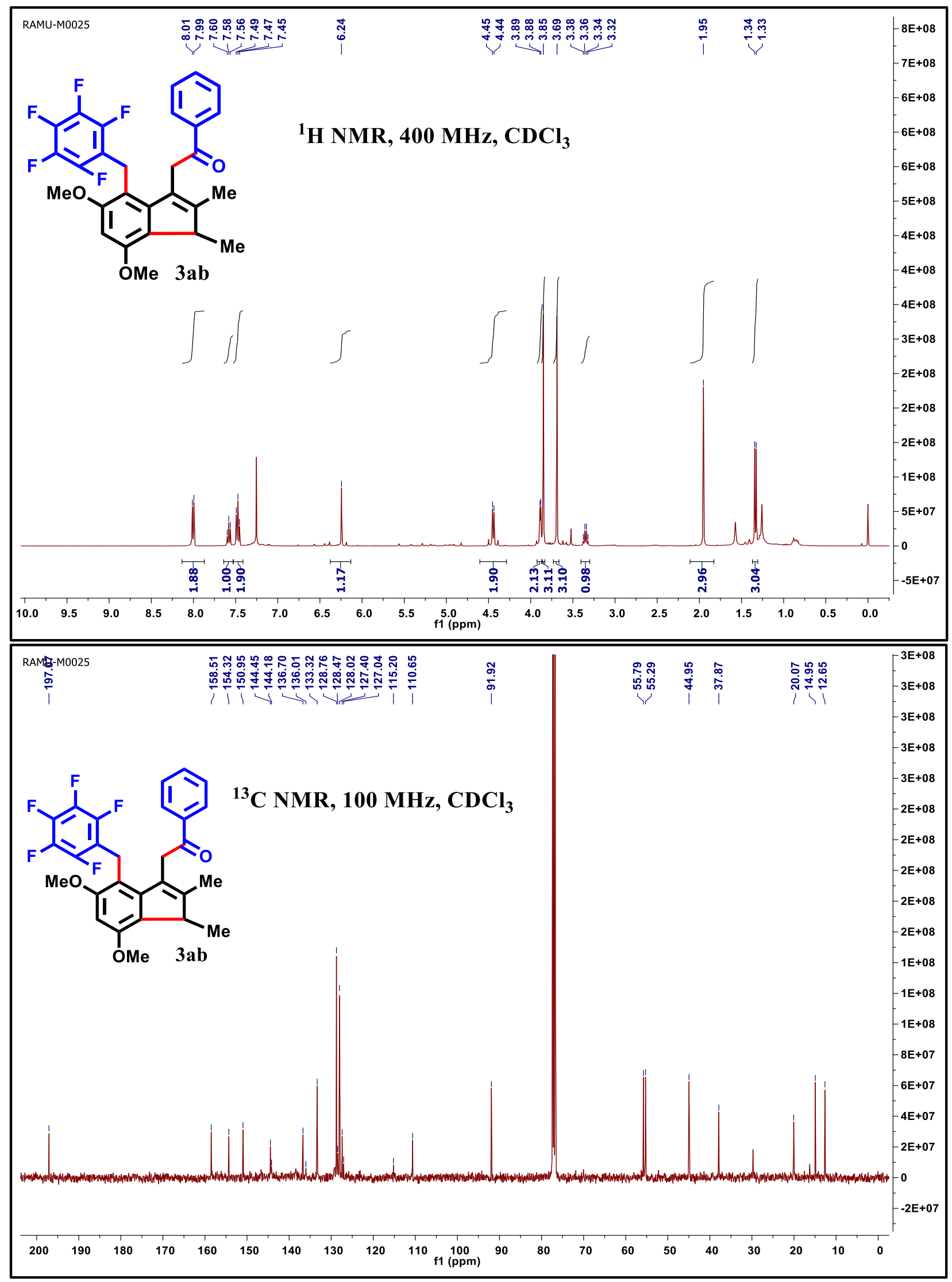



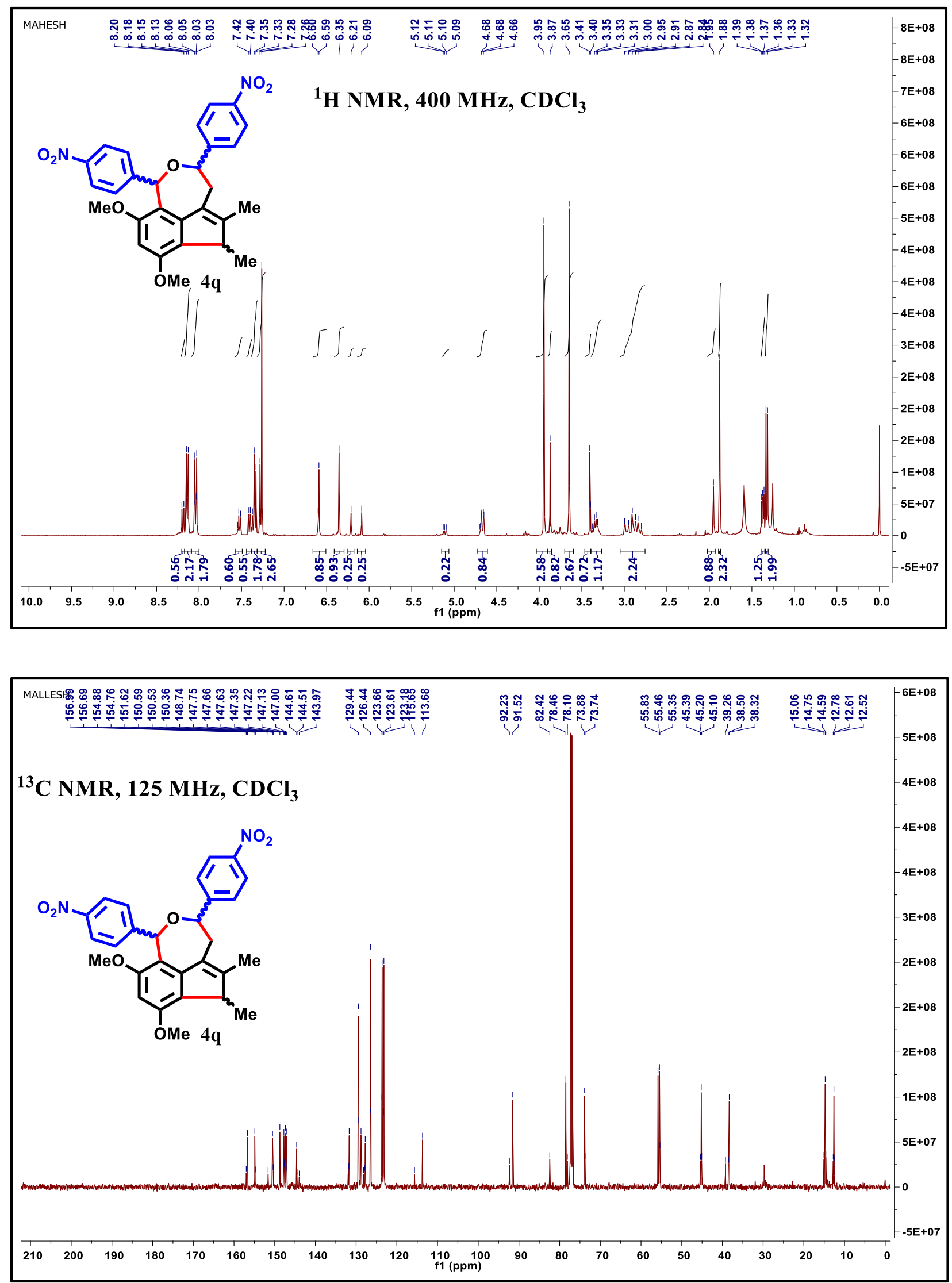

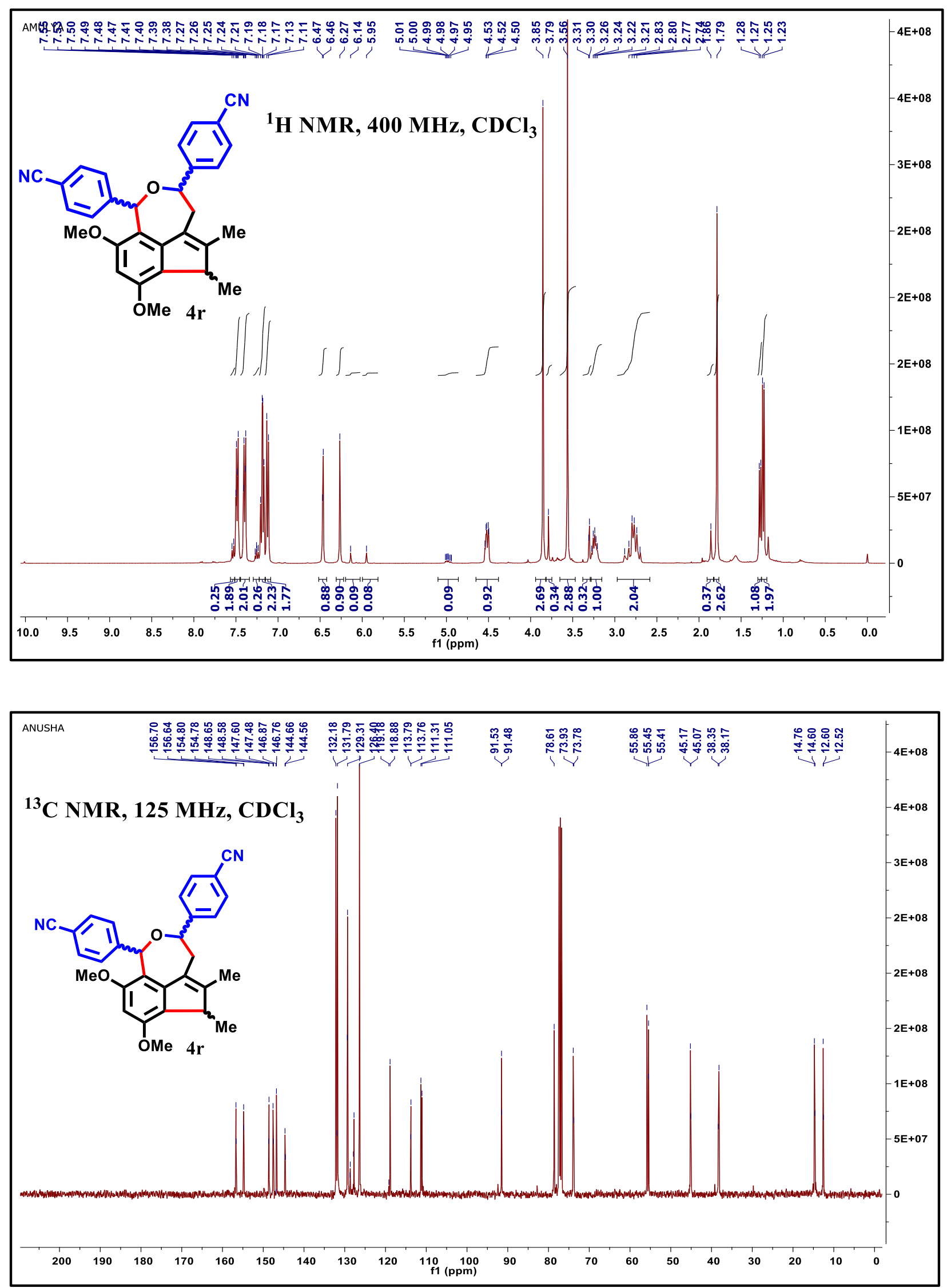

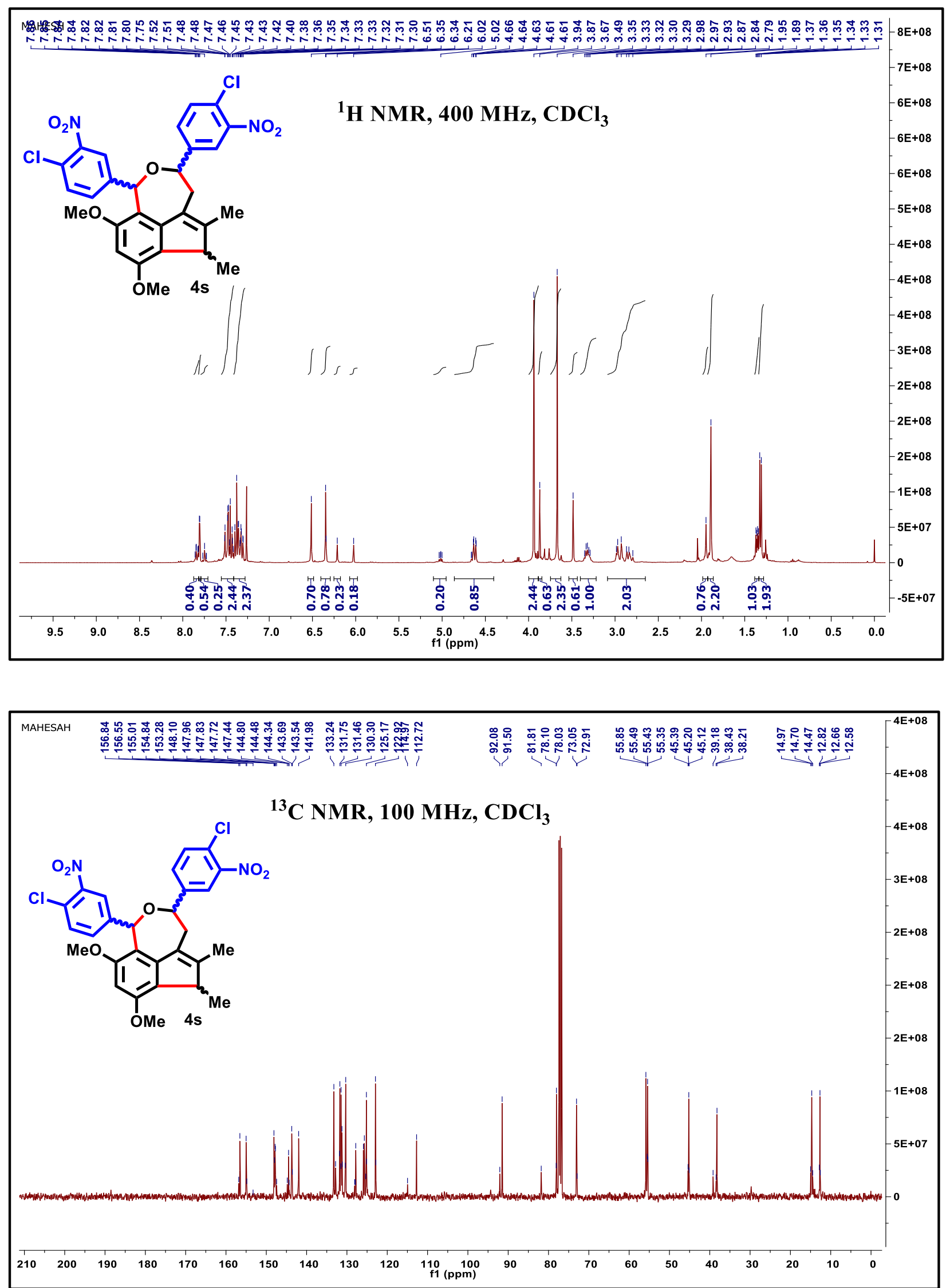

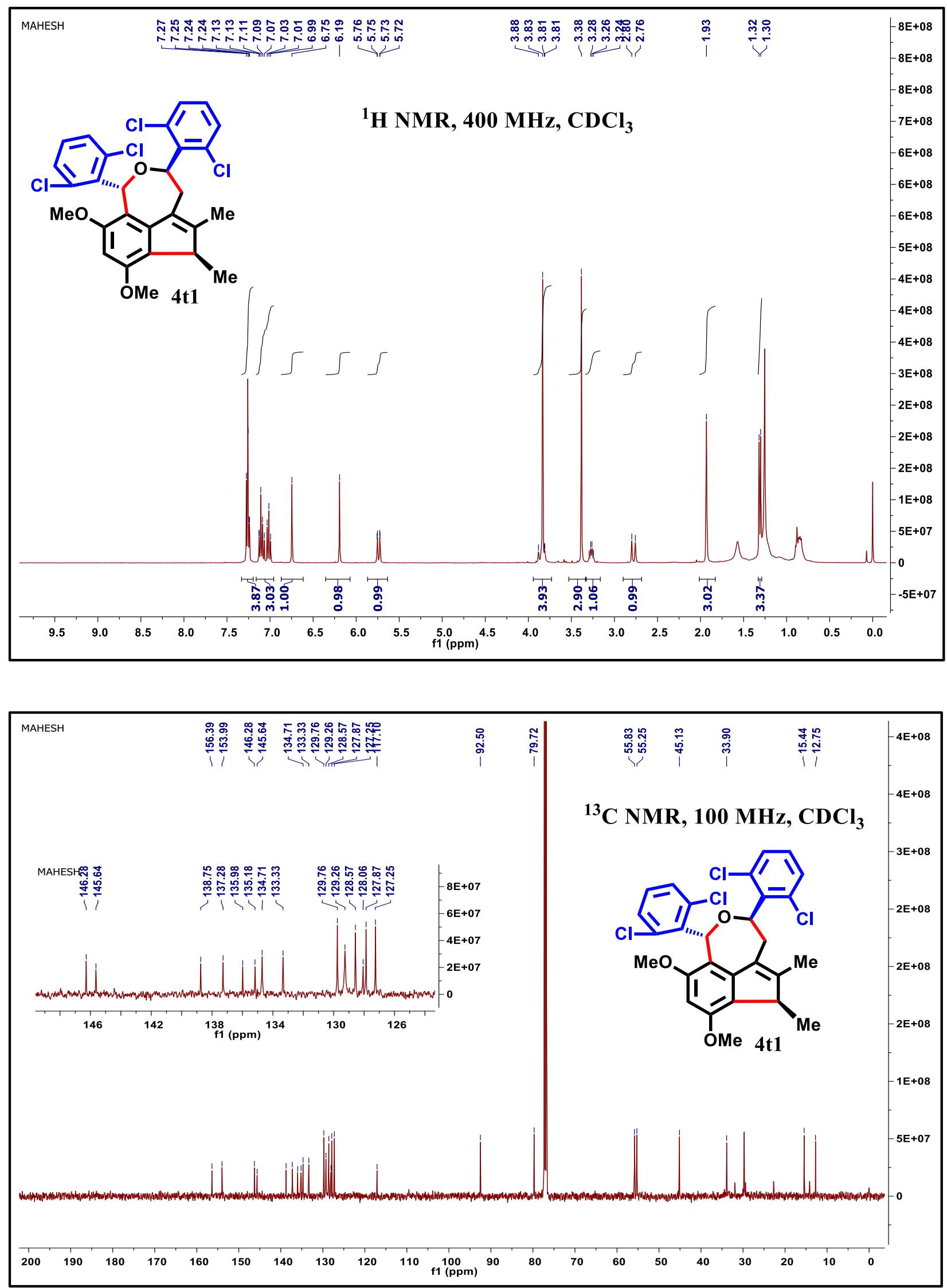

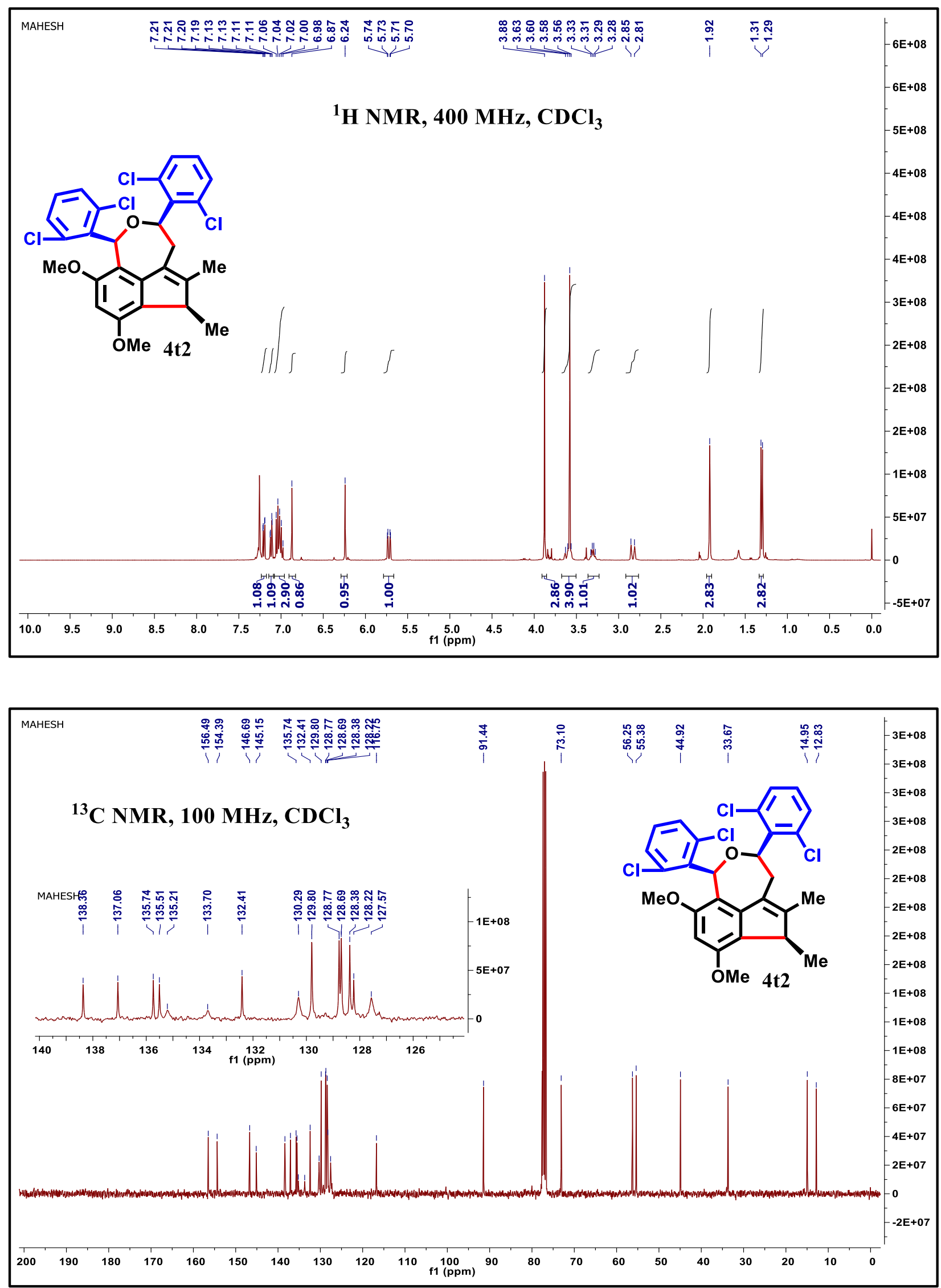

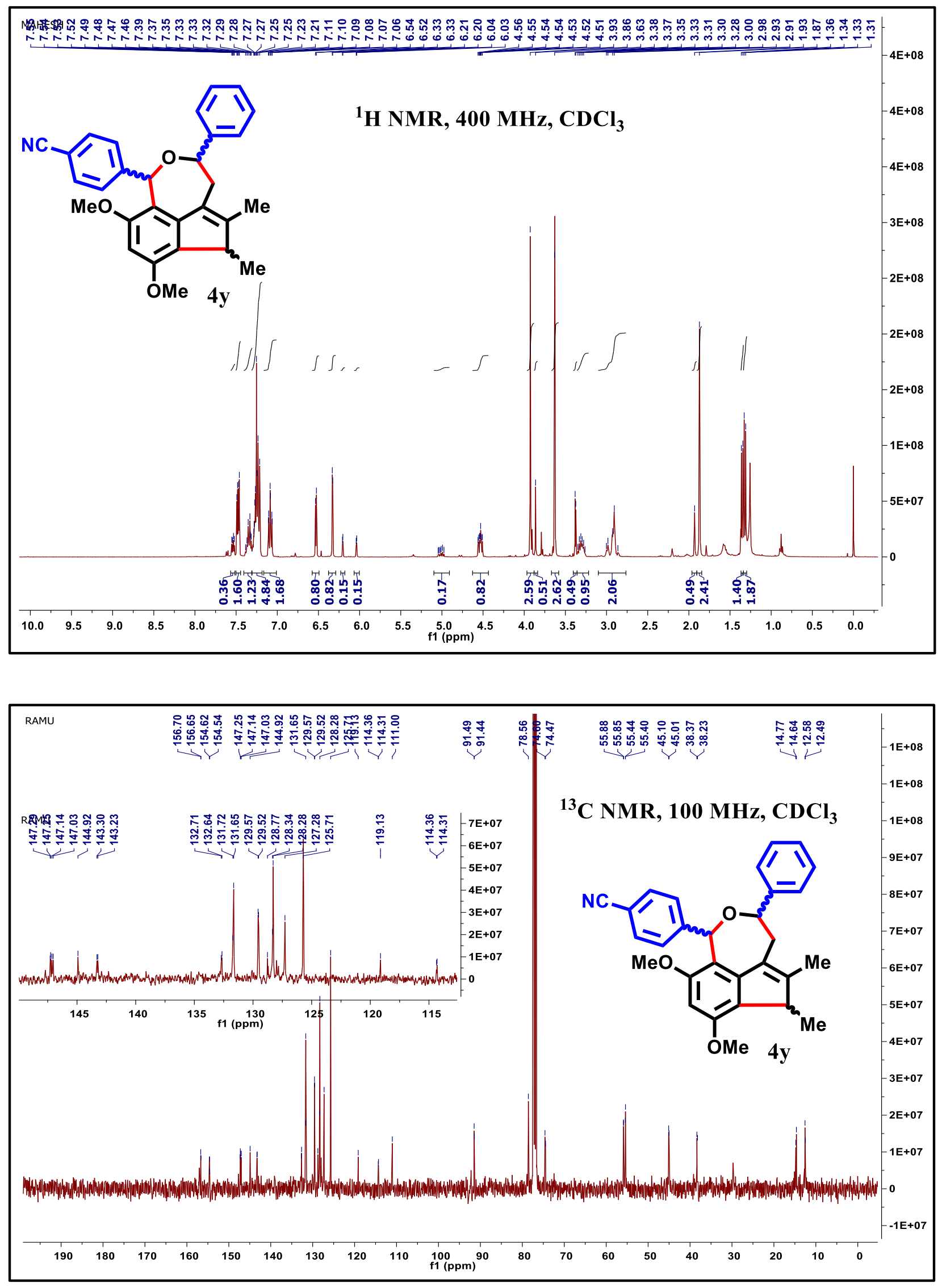

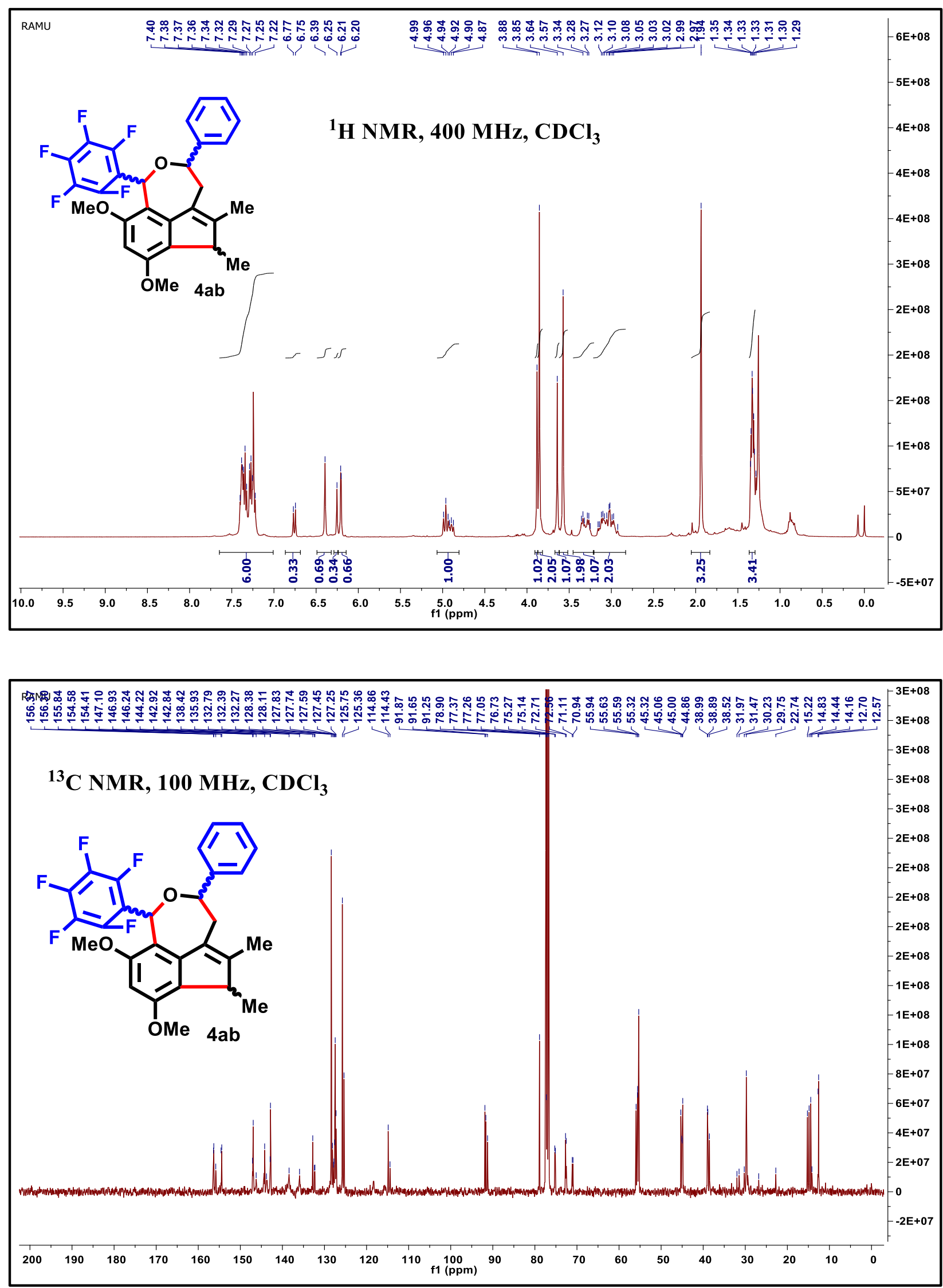


\section{X-ray Crystallographic Data}

\section{Crystallographic data for 4a1:}

Benzaldehyde derived oxepine 4a1 (50 mg) was dissolved in EtOAc (3 mL) and transferred into a transparent chamber through filtration and added $0.5 \mathrm{~mL}$ of pentane. The clear solution was covered with thin parafilm and stored in $500 \mathrm{~mL}$ beaker and $100 \mathrm{~mL}$ of hexane was added outside of beaker to cool the beaker and kept on bench for 10 days. The slow evaporation of solvent was observed and found grey color crystal solids in chamber. The crystal was dried at room temperature over several hours to remove small portion of solvent.

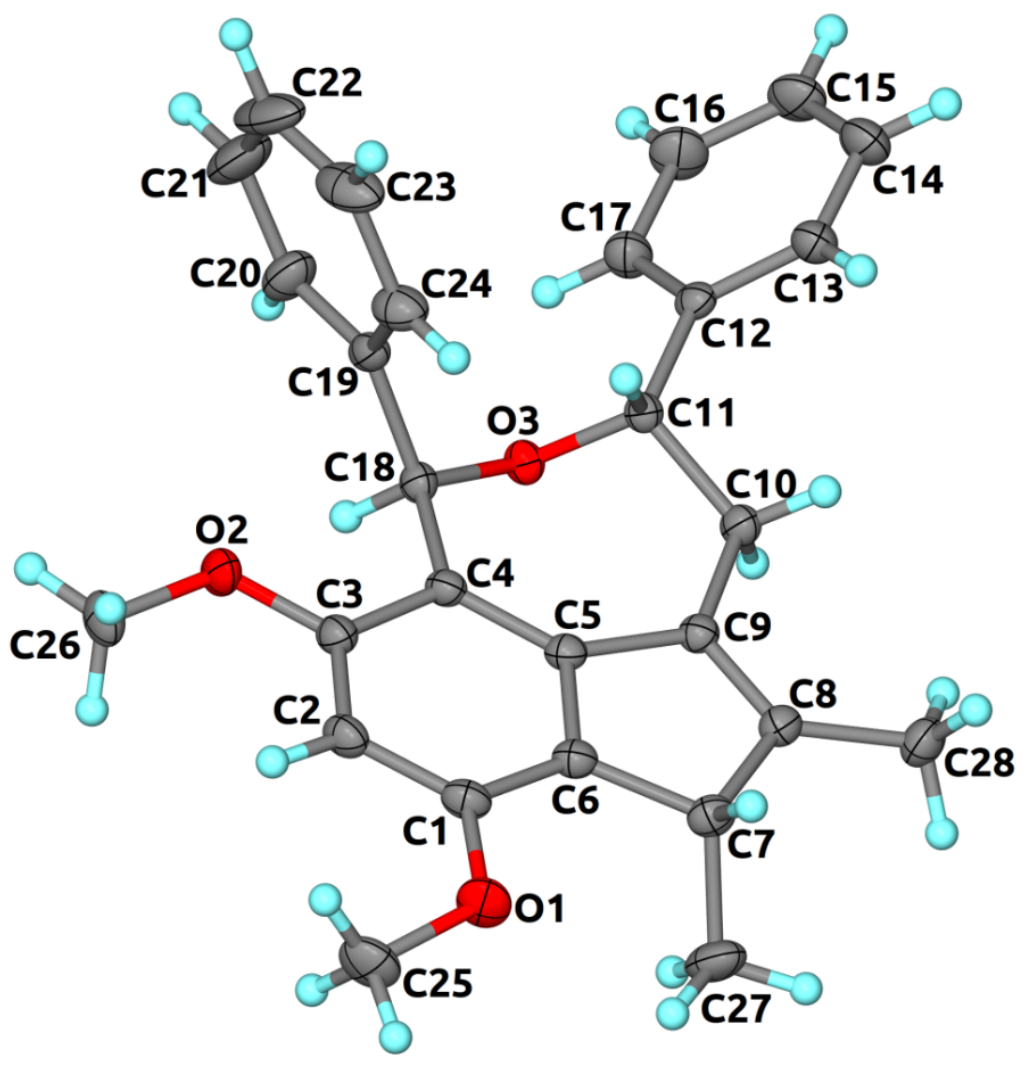


ORTEP diagram of $\mathbf{4 a 1}$ with the atom-numbering scheme. Displacement ellipsoids are drawn at the $30 \%$ probability level and $\mathrm{H}$ atoms are shown as small spheres of arbitrary radius. Contains the supplementary crystallographic data for this paper. Compound crystallized in the triclinic centrosymmetric space group with SSR and RRS configurations at C7, C11 and C18 atoms, confirming its racemic nature. CCDC 1887604 contains the supplementary crystallographic data.

\section{Data Collection and Structure Refinement details:}

Single crystal X-ray data for two compounds were collected at room temperature on a Bruker D8 QUEST equipped with a four circle kappa diffractometer and Photon 100 detector. An Insmicrofocus Mo source ( $=0.71073 \AA$ ) supplied the multi-mirror monochromated incident beam. A combination of Phi and Omega scans were used to collect the necessary data. Unit cell dimensions were determined using 8834 reflections. Integration and scaling of intensity data were accomplished using SAINT program. ${ }^{2}$ The structures were solved by Direct Methods using APEX3 (Bruker, 2016) and refinement was carried out by full-matrix least-squares technique using SHELXL-2018/3..$^{3-4}$ Anisotropic displacement parameters were included for all nonhydrogen atoms. All $\mathrm{H}$ atoms were positioned geometrically and treated as riding on their parent C atoms with C-H distances of $0.93--0.97 \AA$, and with $\mathrm{U}_{\text {iso }}(\mathrm{H})=1.2 \mathrm{U}_{\text {eq }}(\mathrm{C})$ or $1.5 \mathrm{U}_{\text {eq }}$ for methyl atoms. CCDC 1887604 contains the supplementary crystallographic data for this paper which can be obtained free of charge at https://summary.ccdc.cam.ac.uk/structure-summary-form or from the Cambridge Crystallographic Data Centre (CCDC), 12 Union Road, Cambridge CB2 1EZ, UK; fax: +44(0) 1223336 033; email: deposit@ccdc.cam.ac.uk. 


\section{Table S1: Crystal data and structure refinement.}

$\begin{array}{ll}\text { Identification code } & \mathbf{4 a 1} \\ \text { Chemical formula } & \mathrm{C}_{28} \mathrm{H}_{28} \mathrm{O}_{3} \\ \text { Molecular weight } & 412.50 \\ \text { Temperature } & 293(2) \mathrm{K} \\ \text { Wavelength } & 0.71073 \AA \\ \text { Crystal system ; space group } & \text { triclinic } ; \mathrm{P}-1 \\ & \mathrm{a}=9.206(7) \AA \\ & \mathrm{b}=10.422(9) \AA \\ & \mathrm{c}=13.489(11) \AA \\ \text { Unit cell dimensions } & \alpha=70.70(3)^{\circ} \\ & \beta=86.07(3)^{\circ} \\ & \gamma=64.49(4)^{\circ} \\ \text { Volume } & 1098.2(16) \AA^{3} \\ \text { Z, Calculated density } & 2,1.247 \mathrm{~g} / \mathrm{cm}^{3} \\ \text { Absorption coefficient } & 0.0801 / \mathrm{mm}^{\circ} \\ \text { F(000) } & 440 \\ \text { Theta range for data collection } & 2.298^{\circ} \text { to } 25.000^{\circ} \\ \text { Limiting indices } & -10<=\mathrm{h}<=10 ;-12<=\mathrm{k}<=12 ;-16<=1<=16 \\ \text { Reflection collected / unique } & 20845 / 3859[\mathrm{R}(\mathrm{int})=0.0724] \\ \text { Completeness to theta max } & 100.0 \% \\ \text { Refinement method } & \mathrm{Full}-\mathrm{matrix} \text { least-square on } \mathrm{F}^{2} \\ \text { Data / restraints / parameters } & 3859 / 0 / 285 \\ \text { Goodness of fit on } \mathrm{F}^{2} & 1.243 \\ \text { Final R indices [I }>2 \text { sigma(I) }] & \mathrm{R} 1=0.0520 ; \mathrm{wR} 2=0.1573 \\ \text { Final R indices [all data] } & \mathrm{R} 1=0.0674 ; \mathrm{wR} 2=0.1722 \\ \text { Largest diff peak and hole } & 0.270 \text { and }-0.239 \mathrm{e} / \AA^{3} \\ \end{array}$

\section{Crystallographic data for $4 \mathrm{t} 2$ :}

2,6-Dichloro benzaldehyde derived oxepine $\mathbf{4 t 2}(110 \mathrm{mg}$, white solid) was dissolved in $20 \%$ EtOAc/hexane $(5 \mathrm{~mL})$ and transferred into a transparent chamber through filtration and added few drops of pentane. The clear solution was covered with thin parafilm and stored in $250 \mathrm{~mL}$ beaker and $50 \mathrm{~mL}$ of hexane was added outside of beaker to cool the beaker and kept on bench 
for a week. The slow evaporation of solvent was observed and found thin colorless solid crystals in chamber. The crystal was dried at room temperature over several hours to remove small portion of solvent.

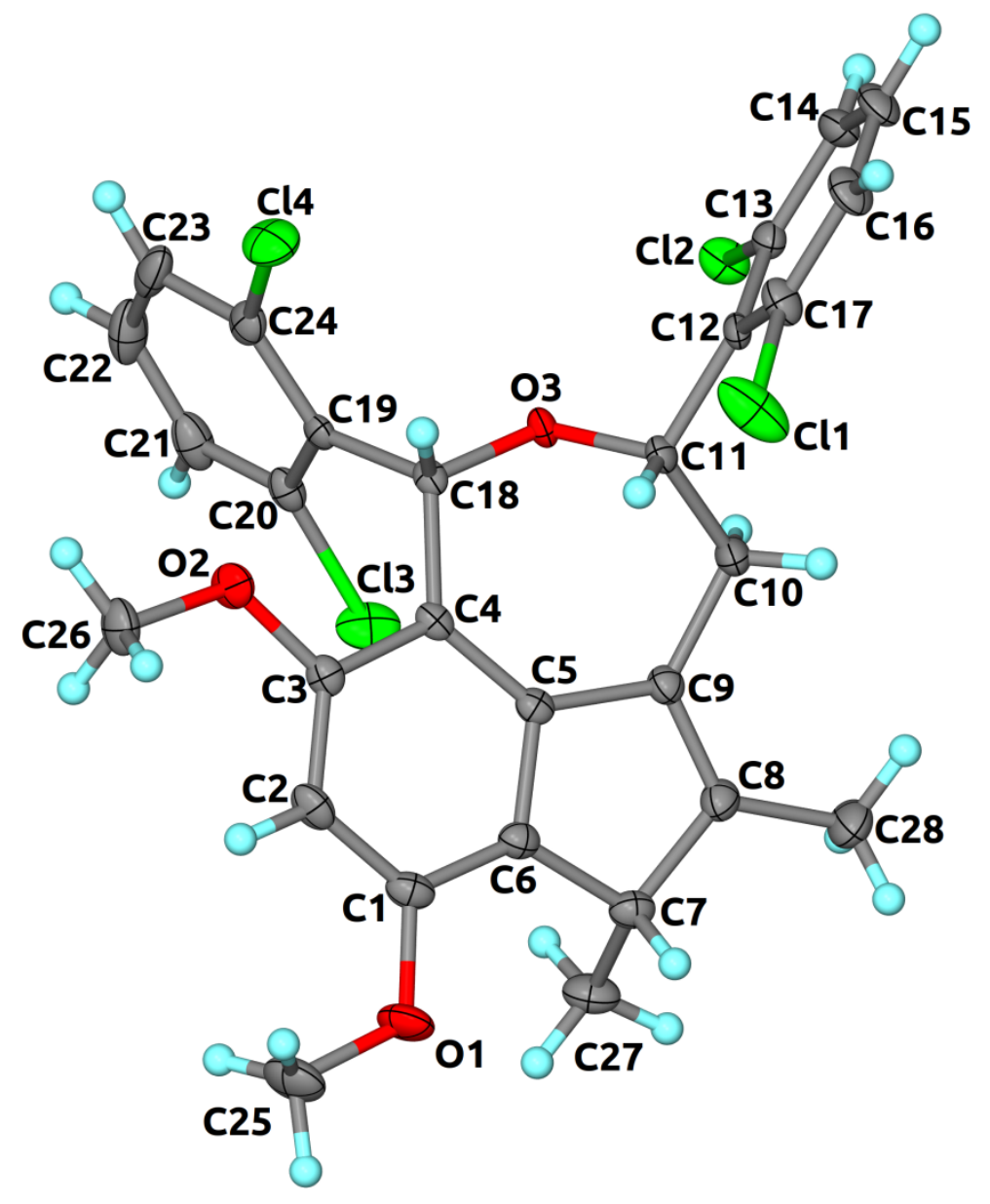

ORTEP diagram of $\mathbf{4 t 2}$ with the atom-numbering scheme. Displacement ellipsoids are drawn at the $30 \%$ probability level and $\mathrm{H}$ atoms are shown as small spheres of arbitrary radius. Contains the supplementary crystallographic data for this paper. Compound crystallized in the triclinic centrosymmetric space group with SSR and RRS configurations at C7, C11 and C18 atoms, confirming its racemic nature. CCDC 1887605 contains the supplementary crystallographic data. 
Data Collection and Structure Refinement details: Single crystal X-ray data for two compounds were collected at room temperature on a Bruker D8 QUEST equipped with a four circle kappa diffractometer and Photon 100 detector. An I $\mu$ smicrofocus Mo source ( $=0.71073 \AA)$ supplied the multi-mirror monochromated incident beam. A combination of Phi and Omega scans were used to collect the necessary data. Unit cell dimensions were determined using 6756 reflections. Integration and scaling of intensity data were accomplished using SAINT program. ${ }^{2}$ The structures were solved by Direct Methods using APEX3 software (Bruker, 2016) and refinement was carried out by full-matrix least-squares technique using SHELXL-2018/3.3-4 Anisotropic displacement parameters were included for all non-hydrogen atoms. All $\mathrm{H}$ atoms were positioned geometrically and treated as riding on their parent $\mathrm{C}$ atoms with $\mathrm{C}-\mathrm{H}$ distances of 0.93--0.97 $\AA$, and with $\mathrm{U}_{\text {iso }}(\mathrm{H})=1.2 \mathrm{U}_{\text {eq }}(\mathrm{C})$ or $1.5 \mathrm{U}_{\text {eq }}$ for methyl atoms. CCDC 1887605 contains the supplementary crystallographic data for this paper which can be obtained free of charge at https://summary.ccdc.cam.ac.uk/structure-summary-form or from the Cambridge Crystallographic Data Centre (CCDC), 12 Union Road, Cambridge CB2 1EZ, UK; fax: +44(0) 1223336 033; email: deposit@ccdc.cam.ac.uk.

\section{Table S2: Crystal data and structure refinement.}

$\begin{array}{ll}\text { Identification code } & \mathrm{KA} 319 \\ \text { Chemical formula } & \mathrm{C}_{28} \mathrm{H}_{24} \mathrm{C}_{14} \mathrm{O}_{3} \\ \text { Molecular weight } & 550.27 \\ \text { Temperature } & 293(2) \mathrm{K} \\ \text { Wavelength } & 0.71073 \AA \\ \text { Crystal system ; space group } & \text { Triclinic ; } \mathrm{P}-1 \\ & \mathrm{a}=7.8869(4) \AA \\ & \mathrm{b}=9.3365(5) \AA \\ \text { Unit cell dimensions } & \mathrm{c}=19.4770(11) \AA \\ & \alpha=81.863(2){ }^{\circ} \\ & \beta=80.9818(17)^{\circ} \\ & \gamma=65.5329(17)^{\circ}\end{array}$


Volume

Z, Calculated density

Absorption coefficient

$\mathrm{F}(000)$

Theta range for data collection

Limiting indices

Reflection collected / unique

Completeness to theta max

Refinement method

Data / restraints / parameters

Goodness of fit on $\mathrm{F}^{2}$

Final $\mathrm{R}$ indices $[\mathrm{I}>2 \operatorname{sigma}(\mathrm{I})]$

Final $\mathrm{R}$ indices [all data]

Largest diff peak and hole
$1284.59(12) \AA^{3}$

$2,1.423 \mathrm{~g} / \mathrm{cm}^{3}$

$0.4901 / \mathrm{mm}$

568

$2.125^{\circ}$ to $25.998^{\circ}$

$-8<=\mathrm{h}<=9 ;-11<=\mathrm{k}<=11 ;-23<=1<=23$

$26248 / 5059[\mathrm{R}($ int $)=0.0803]$

$99.9 \%$

Full-matrix least-square on $\mathrm{F}^{2}$

5059 / 0 / 320

1.024

$\mathrm{R} 1=0.0593 ; \mathrm{wR} 2=0.1451$

$\mathrm{R} 1=0.1044 ; \mathrm{wR} 2=0.1678$

0.433 and $-0.428 \mathrm{e} / \AA^{3}$

\section{References:}

1. SMART \& SAINT. Software Reference manuals. Versions 6.28a \& 5.625, Bruker Analytical X-ray Systems Inc., Madison, Wisconsin, U.S.A., 2001.

2. Sheldrick, G. M. SHELXS97 and SHELXL Version 2014/7, http://shelx.uniac.gwdg.de/SHELX/index.php

3. Muller, P, Herbst-Imer, R, Spek, A. L, Schneider, T. R, and Sawaya, M. R. Crystal Structure Refinement: A Crystallographer's Guide to SHELXL. Muller, P. Ed. 2006 Oxford University Press: Oxford, New York, pp. 57-91. 